\title{
Measurements of cnidae from sea anemones (Cnidaria: Actiniaria), III: ranges and other measures of statistical dispersion, their interrelations and taxonomic relevance*
}

\author{
R. B. WILLIAMS \\ Norfolk House, Western Road, Tring, Herts. HP23 4BN, United Kingdom.
}

\begin{abstract}
SUMMARY: This is the third of a series of papers examining the taxonomic relevance of some statistical treatments of measurements of cnidae from sea anemones (Actiniaria). Some cnida lengths from fresh tissue samples (column ectoderm, tentacles or acontia) from Nematostella vectensis, Haliplanella lineata, Sagartia elegans, Metridium senile, Cereus pedunculatus, Sagartia troglodytes, Anthopleura thallia, Urticina eques and Sagartiogeton laceratus were measured. Five measures of statistical dispersion (sample standard deviation, coefficient of variation, observed sample range, standard range, and $99 \%$ probable maximum value of the standard range) were calculated, and their interrelations and potential applications were appraised. It has long been the convention to use the largest and smallest cnida sizes (observed sample range) from tissue samples in attempts to establish differences between actiniarian taxa. However, such data do not reflect the true extremes of a population range. In the present study, the $99 \%$ probable maximum value of the standard range for a standard abundance of 1,000 gave the greatest and, therefore, the most cautious estimate of a population range of cnida sizes for a species. This maximum standard range is the only measure of dispersion of cnida sizes that may be used validly to demonstrate that anemone specimens are of different species, and then only if there is no overlap between the extreme cnida sizes being compared. However, partial or complete overlaps of cnida size extremes do not necessarily indicate that specimens are conspecific; other taxonomic characters must also be considered. Coefficients of variation may provide valuable clues as to the homogeneity or heterogeneity of samples of cnida measurements. This paper should be read in conjunction with the first two in this series, which address the taxonomic relevance of differences between mean cnida sizes (Williams, 1996, Sci. Mar., 60: 339-351; 1998, Sci. Mar., 62: 361-372).
\end{abstract}

Key words: Actiniaria, cnidae, measurements, ranges, statistical dispersion, statistics, taxonomy.

\section{INTRODUCTION}

The fundamental characteristic of members of the phylum Cnidaria is their possession of stinging cells called cnidae, of which there are many types (Mariscal, 1974). The cnidome of a cnidarian is an inventory of all the cnida types present in its tissues (Weill, 1926). The cnidome may be valuable as a taxonomic character in some groups of Cnidaria, but

\footnotetext{
*Received January 15, 1999. Accepted October 8, 1999.
}

the value of additional information on cnida sizes, conventionally included in species descriptions of sea anemones (Actiniaria) since it was first suggested by Carlgren (1900), is controversial (Fautin, 1988). The first person (Weill, 1934a, 1934b) to devise a comprehensive classification system for cnidae considered cnida sizes to be of little taxonomic value (Weill, 1934b: 637).

An extensive statistical study of actiniarian cnidae (Williams, 1996, 1998) showed that the frequency distributions of random samples of lengths of cnidae 
of a single type tend to be normal (Gaussian). It was recommended that mean cnida sizes should not be used in isolation from other taxonomic characters to differentiate anemone species, because statistically significant differences may occur between replicate samples from the same specimen, and also between samples from different specimens of the same species. Furthermore, no predictable relations between the sizes of conspecific anemones and the mean lengths of their cnidae were established, either for sexually or asexually reproducing species.

A further assessment of measurements of actiniarian cnidae has now been completed. Because previous work (Williams, 1996, 1998) indicated that inferential significance tests based on the central parameter of a normal frequency distribution, i.e., the mean cnida length, were of little value on their own in taxonomic studies, and indeed might lead to wrong conclusions, a different statistical approach was investigated. For nearly a century, it has been the common practice for researchers to use, in addition to cnidomes, the largest and smallest cnida sizes in the range of each type observed in tissue samples in attempts to establish differences between actiniarian taxa. The statistical validity of such range comparisons has never been established. Therefore, in the present study, five measures of dispersion (sample standard deviation, coefficient of variation, observed sample range, standard range, and 99\% probable maximum value of the standard range) based on the normal (Gaussian) distribution were examined, and their interrelations and interpretations were appraised for taxonomic and other purposes.

\section{MATERIAL AND METHODS}

The methods of obtaining independent, random, homogeneous samples of cnida measurements from standard tissue samples taken from live sea anemones followed those established by Williams (1996). The species of anemones examined and the dataset codes for the cnida lengths in each tissue sample examined were Nematostella vectensis Stephenson (dataset NEMATO1), Haliplanella lineata (Verrill) (HALIP1), Metridium senile (Linnaeus) (METRID1), Cereus pedunculatus (Pennant) (CEREUS1), Sagartia elegans (Dalyell) (SAGART1 and SAGART6), Sagartia troglodytes (Price) (SAGART7), Anthopleura thallia (Gosse) (ANTHO1), Urticina eques (Gosse) (URTIC3) and Sagartiogeton laceratus (Dalyell) (SAGETON1).
The tissues that were sampled and the types of cnidae measured are given in Tables 1-11. The specimens of anemones from which the tissue samples were taken were the same as those studied by Williams (1996, 1998); details of the sources and sizes of specimens and the full descriptive statistics of each dataset of cnida lengths may be obtained from those publications.

At least 40 cnidae of each predetermined type, as recommended by Williams (1996), were measured in each tissue sample. Statistical analyses were carried out using MINITAB Statistical Software, Release 8, or an electronic calculator for simpler calculations. Explanations of the statistical theory and calculations employed are given where appropriate in the results. The preselected significance level for rejection of null hypotheses in any inferential statistical tests was $5 \%(\mathrm{P}=0.05)$.

\section{RESULTS AND DISCUSSION}

\section{Mathematical interrelations between measures of statistical dispersion within samples of cnida lengths}

It has already been shown that differences demonstrated, by classic inferential statistical tests, between mean lengths of samples of single cnida types cannot be used in isolation to distinguish actiniarian species (Williams, 1996, 1998). Might there be any other parameters of cnida measurements that may be used validly to distinguish specimens of different species? Previous authors since the time of Carlgren (1900) have frequently assumed that if the observed size extremes ("range") of a particular cnida type from one specimen do not, or only slightly, overlap those of a corresponding type from another, then the specimens are likely to represent different species. Note that, strictly, a range is expressed by a single value, the difference between the largest and the smallest observed values; the largest and smallest values are here referred to as the extreme values (or extremes).

A statistically normal frequency distribution is completely determined by only two parameters, the mean and the standard deviation. Calculation of the sample standard deviation is essential to carry out significance tests for differences between means of two statistical populations. However, the observed sample range and its extreme values alone provide no information about the statistical distribution of 
the data. For a normal distribution, though, there is a mathematical relation between the standard deviation and the range, which allows either to be estimated from the other (Williams, 1998: Appendix II). The taxonomic significance of any cnida size range overlaps is a matter of experience and judgement, and is therefore subjective (see Fautin, 1988). Because of this, a statistical approach has been adopted here to investigate measures of dispersion in more detail and to introduce some degree of objectivity. The observed extremes of a range of cnida lengths in fact comprise just one of several measures of statistical dispersion, all of which are mathematically related to the standard deviation of a normal frequency distribution. It is important, therefore, to establish the relations between the five different measures of dispersion examined here.

The measures of dispersion examined were the sample standard deviation; the coefficient of variation; the observed sample range; the standard range; and the $99 \%$ probable maximum value of the standard range. They are mathematically related thus:

1) The sample standard deviation is calculated from the observed individual data. However, if only the extreme values of the observed range and number of observations are available, the standard deviation may be estimated from the observed sample range.

2) The coefficient of variation is calculated by expressing the standard deviation as a percentage of the mean of the same sample.

3) The standard range may be estimated directly from the sample standard deviation or, with less confidence, indirectly from the standard deviation estimated from the observed sample range.

4) The $99 \%$ probable maximum value of the standard range may be estimated from the sample standard deviation or, less satisfactorily, from the standard deviation estimated from the observed sample range.

Practical examples of these relations in calculations are given below and the applications and interpretations of the various measures of dispersion, using data presented in this paper, are discussed hereafter.

\section{The sample standard deviation and its calculation}

\section{Calculation of standard deviation from the observed individual data}

The sample standard deviation, with the sample mean, completely describes a normal frequency distribution, but the standard deviation is not a value that intuitively conveys any special meaning except that, for samples with roughly equal means, the smaller the value of the standard deviation, the less variable are the individual observations. The sample standard deviations must be calculated (see 1) above) if it is required to compare the means of two samples using observed data. The method of calculation may be obtained from any basic statistics textbook. The variabilities of the two samples may be compared by squaring the standard deviations to obtain the variances and carrying out a two-tailed F-test for equality of two variances (Snedecor and Cochran, 1967). In fact, statistical equality of the sample variances is a requirement for the valid use of a $t$-test with a pooled standard deviation (see Williams, 1998). If the samples have unequal variances, a modified $t$-test is required for a valid comparison of means (Snedecor and Cochran, 1980).

\section{Estimation of standard deviation from the observed} sample range

In published data, sometimes only the size of a sample and its extreme values are provided, from which the range may be calculated, and the standard deviation may then be estimated (see 1) above). The relation between the range and standard deviation in this context was introduced by Williams (1998: Appendix II). Although Fautin (1988) stated that random sampling is not required for range data, strictly the predictable relation between standard deviation and range is only valid for random, normally distributed samples.

Tables are available from which a standard deviation may be estimated by multiplying the range of a random sample of size $n$ from a normal population by $a_{n}$ (e.g., Lindley and Miller, 1964: Table 6). For instance, for a sample of 10 observations, $a_{n}=0.3249$. Therefore, for a sample of 10 with a range of $5 \mu \mathrm{m}$, the standard deviation is given by $5 \times 0.3249=1.6245 \mu \mathrm{m}$. Conversely, the mean range in samples of size $n$ from a normal population is equal to the standard deviation of the population divided by $a_{n}$ (Lindley and Miller, 1964: 7). It can be seen from Snedecor and Cochran (1967: Table 2.4.1) that the efficiency of a range as an estimator of a standard deviation is $100 \%$ for a sample of 2, falling to $85 \%$ for a sample of 10. For samples of between 11 and 50, efficiency progressively falls yet further to $49 \%$. 
TABLE 1. - Statistical parameters of dataset NEMATO1 (Williams, 1996), which comprises lengths of basitrich nematocysts from a tentacle tip of Nematostella vectensis. EstM = mean estimated from range; \% diffM = percentage difference between estimated mean and mean; SD = sample standard deviation; EstSD = standard deviation estimated from range; \% diffSD = percentage difference between estimated standard deviation and sample standard deviation; $\mathrm{CoV}=$ coefficient of variation (\%); Min = minimum extreme value; Max = maximum extreme value. All parameters except $n, \mathrm{CoV}$ and percentage differences in $\mu \mathrm{m}$ (accuracy $\pm 0.83 \mu \mathrm{m}$ ). There were no statistically significant differences between the means of any independent subsets of 5 and the overall mean $(19.4 \mu \mathrm{m})$ of the whole dataset.

\begin{tabular}{|c|c|c|c|c|c|c|c|c|c|c|c|}
\hline Subset & $\mathrm{n}$ & Mean & EstM & $\%$ diffM & $\mathrm{SD}$ & EstSD & $\%$ diffSD ${ }^{a}$ & $\mathrm{CoV}$ & Min & $\operatorname{Max}$ & Range \\
\hline 1 & 5 & 19.7 & 19.7 & 0.0 & 1.27 & 1.07 & -15.7 & 6.4 & 18.4 & 20.9 & 2.5 \\
\hline 2 & 5 & 18.7 & 18.4 & -1.6 & 1.27 & 1.42 & +11.8 & 6.8 & 16.7 & 20.0 & 3.3 \\
\hline 3 & 5 & 18.7 & 19.2 & +2.7 & 2.10 & 2.15 & +2.4 & 11.2 & 16.7 & 21.7 & 5.0 \\
\hline 4 & 5 & 18.9 & 19.2 & +1.6 & 1.83 & 2.15 & +17.5 & 9.7 & 16.7 & 21.7 & 5.0 \\
\hline 5 & 5 & 19.4 & 18.8 & -3.1 & 1.81 & 1.81 & 0.0 & 9.3 & 16.7 & 20.9 & 4.2 \\
\hline 6 & 5 & 20.5 & 20.9 & +2.0 & 1.83 & 2.15 & +17.5 & 8.9 & 18.4 & 23.4 & 5.0 \\
\hline 7 & 5 & 19.7 & 20.5 & +3.8 & 1.12 & 1.07 & -4.5 & 5.7 & 19.2 & 21.7 & 2.5 \\
\hline 8 & 5 & 19.5 & 19.7 & +0.8 & 1.27 & 1.07 & -15.7 & 6.5 & 18.4 & 20.9 & 2.5 \\
\hline 9 & 5 & 18.9 & 18.8 & -0.8 & 1.12 & 1.07 & -4.5 & 5.9 & 17.5 & 20.0 & 2.5 \\
\hline 10 & 5 & 19.7 & 19.6 & -0.5 & 1.73 & 1.81 & +4.6 & 8.8 & 17.5 & 21.7 & 4.2 \\
\hline 1 & 5 & 19.7 & 19.7 & 0.0 & 1.27 & 1.07 & -15.7 & 6.4 & 18.4 & 20.9 & 2.5 \\
\hline $1-2$ & 10 & 19.2 & 18.8 & -2.1 & 1.31 & 1.36 & +3.8 & 6.8 & 16.7 & 20.9 & 4.2 \\
\hline $1-3$ & 15 & 19.0 & 19.2 & +1.1 & 1.55 & 1.44 & -7.1 & 8.2 & 16.7 & 21.7 & 5.0 \\
\hline $1-4$ & 20 & 19.0 & 19.2 & +1.1 & 1.58 & 1.34 & -15.2 & 8.3 & 16.7 & 21.7 & 5.0 \\
\hline $1-6$ & 30 & 19.3 & 20.1 & +3.9 & 1.70 & 1.64 & -3.5 & 8.8 & 16.7 & 23.4 & 6.7 \\
\hline $1-7$ & 35 & 19.4 & 20.1 & +3.4 & 1.62 & 1.59 & -1.9 & 8.3 & 16.7 & 23.4 & 6.7 \\
\hline $1-8$ & 40 & 19.4 & 20.1 & +3.4 & 1.56 & 1.55 & -0.6 & 8.1 & 16.7 & 23.4 & 6.7 \\
\hline $1-9$ & 45 & 19.3 & 20.1 & +3.9 & 1.52 & 1.52 & 0.0 & 7.9 & 16.7 & 23.4 & 6.7 \\
\hline $1-10$ & 50 & 19.4 & 20.1 & +3.4 & 1.53 & 1.49 & -2.6 & 7.9 & 16.7 & 23.4 & 6.7 \\
\hline
\end{tabular}

a All comparisons of SD and EstSD not statistically significant $(\mathrm{P}>0.05)$.

TABLE 2. - Statistical parameters of dataset HALIP1 (Williams, 1996), which comprises lengths of microbasic amastigophore nematocysts from a tentacle tip of Haliplanella lineata. All abbreviations for headings as for Table 1 . All parameters except $n$, CoV and percentage differences in $\mu \mathrm{m}$ (accuracy $\pm 0.83 \mu \mathrm{m}$ ). There were no statistically significant differences between the means of any independent subsets of 5 and the overall mean $(8.3 \mu \mathrm{m})$ of the whole dataset.

\begin{tabular}{|c|c|c|c|c|c|c|c|c|c|c|c|}
\hline Subset & $\mathrm{n}$ & Mean & EstM & $\%$ diffM & SD & EstSD & $\% \operatorname{diffSD}{ }^{a}$ & $\mathrm{CoV}$ & Min & Max & Range \\
\hline 1 & 5 & 7.5 & 7.5 & 0.0 & 1.32 & 1.46 & +10.6 & 17.6 & 5.8 & 9.2 & 3.4 \\
\hline 2 & 5 & 7.4 & 7.5 & +1.4 & 1.24 & 1.46 & +17.7 & 16.7 & 5.8 & 9.2 & 3.4 \\
\hline 3 & 5 & 8.5 & 8.8 & +2.9 & 0.92 & 1.07 & +16.3 & 10.8 & 7.5 & 10.0 & 2.5 \\
\hline 4 & 5 & 9.2 & 9.5 & $\begin{array}{r}+2.7 \\
\end{array}$ & 0.59 & 0.90 & $\begin{array}{r}52.5 \\
\end{array}$ & 6.4 & 8.4 & 10.5 & 2.1 \\
\hline 5 & 5 & 8.9 & 9.2 & +3.4 & 1.27 & 1.46 & +15.0 & 14.2 & 7.5 & 10.9 & 3.4 \\
\hline 6 & 5 & 8.4 & 8.4 & 0.0 & 0.00 & 0.00 & 0.0 & 0.0 & 8.4 & 8.4 & 0.0 \\
\hline 7 & 5 & 8.9 & 9.5 & +6.2 & 0.75 & 0.90 & +20.0 & 8.4 & 8.4 & 10.5 & 2.1 \\
\hline 8 & 5 & 8.5 & 8.4 & -1.8 & 0.70 & 0.73 & +4.3 & 8.2 & 7.5 & 9.2 & 1.7 \\
\hline 9 & 5 & 8.4 & 7.9 & -6.0 & 1.56 & 1.81 & +16.0 & 18.6 & 5.8 & 10.0 & 4.2 \\
\hline 10 & 5 & 7.8 & 7.5 & -3.8 & 1.27 & 1.46 & +15.0 & 16.3 & 5.8 & 9.2 & 3.4 \\
\hline 1 & 5 & 7.5 & 7.5 & 0.0 & 1.32 & 1.46 & +10.6 & 17.6 & 5.8 & 9.2 & 3.4 \\
\hline $1-2$ & 10 & 7.4 & 7.5 & +1.4 & 1.21 & 1.10 & -9.1 & 16.4 & 5.8 & 9.2 & 3.4 \\
\hline $1-3$ & 15 & 7.8 & 7.9 & +1.3 & 1.21 & 1.21 & 0.0 & 15.5 & 5.8 & 10.0 & 4.2 \\
\hline $1-4$ & 20 & 8.1 & 8.2 & +0.6 & 1.24 & 1.26 & +1.6 & 15.3 & 5.8 & 10.5 & 4.7 \\
\hline $1-5$ & 25 & 8.3 & 8.4 & +0.6 & 1.25 & 1.31 & +4.8 & 15.1 & 5.8 & 10.9 & 5.1 \\
\hline $1-6$ & 30 & 8.3 & 8.4 & +0.6 & 1.14 & 1.25 & +9.6 & 13.7 & 5.8 & 10.9 & 5.1 \\
\hline $1-7$ & 35 & 8.4 & 8.4 & 0.0 & 1.10 & 1.21 & +10.0 & 13.1 & 5.8 & 10.9 & 5.1 \\
\hline $1-8$ & 40 & 8.4 & 8.4 & 0.0 & 1.05 & 1.18 & $\begin{array}{l}+12.4 \\
\end{array}$ & 12.5 & 5.8 & 10.9 & 5.1 \\
\hline $1-9$ & 45 & 8.4 & 8.4 & 0.0 & 1.10 & 1.16 & +5.5 & 13.1 & 5.8 & 10.9 & 5.1 \\
\hline $1-10$ & 50 & 8.3 & 8.4 & +0.6 & 1.11 & 1.13 & +1.8 & 13.4 & 5.8 & 10.9 & 5.1 \\
\hline
\end{tabular}

${ }^{a}$ All comparisons of SD and EstSD not statistically significant $(\mathrm{P}>0.05)$.

Predictive value of tables for estimation of a standard deviation from an observed sample range

Theoretically, a sample range tends to increase as the sample size increases, although the population standard deviation remains unchanged (Snedecor and Cochran, 1967: 39). Tables 1-9 show the means and sample standard deviations (the determining parameters of a normal frequency distribution) calculated from the complete observed data, as well as 
TABLE 3. - Statistical parameters of dataset SAGART1 (Williams, 1996), which comprises lengths of basitrich nematocysts from a tentacle tip of Sagartia elegans. All abbreviations for headings as for Table 1. All parameters except $n$, CoV and percentage differences in $\mu \mathrm{m}$ (accuracy $\pm 0.83 \mu \mathrm{m}$ ). There were no statistically significant differences between the means of any independent subsets of 5 and the overall mean $(20.5 \mu \mathrm{m})$ of the whole dataset.

\begin{tabular}{|c|c|c|c|c|c|c|c|c|c|c|c|}
\hline Subset & $\mathrm{n}$ & Mean & EstM & $\% \operatorname{diffM}$ & SD & EstSD & $\% \operatorname{diffSD}{ }^{a}$ & $\mathrm{CoV}$ & Min & Max & Range \\
\hline 1 & 5 & 21.0 & 21.3 & +1.4 & 1.09 & 1.07 & -1.8 & 5.2 & 20.0 & 22.5 & 2.5 \\
\hline 2 & 5 & 21.2 & 21.3 & +0.5 & 1.73 & 1.81 & +4.6 & 8.2 & 19.2 & 23.4 & 4.2 \\
\hline 3 & 5 & 19.5 & 19.2 & -1.5 & 0.75 & 0.69 & -8.0 & 3.8 & 18.4 & 20.0 & 1.6 \\
\hline 4 & 5 & 19.7 & 19.2 & -2.5 & 3.16 & 3.61 & +14.2 & 16.0 & 15.0 & 23.4 & 8.4 \\
\hline 5 & 5 & 19.5 & 18.4 & -5.6 & 2.10 & 2.15 & +2.4 & 10.8 & 15.9 & 20.9 & 5.0 \\
\hline 6 & 5 & 21.2 & 20.9 & -1.7 & 0.75 & 0.73 & -2.7 & 3.5 & 20.0 & 21.7 & 1.7 \\
\hline 7 & 5 & 20.0 & 20.1 & +0.3 & 0.84 & 0.73 & -13.1 & 4.2 & 19.2 & 20.9 & 1.7 \\
\hline 8 & 5 & 22.4 & 22.1 & -1.3 & 1.61 & 1.81 & +12.4 & 7.2 & 20.0 & 24.2 & 4.2 \\
\hline 9 & 5 & 20.2 & 20.0 & -1.0 & 2.16 & 2.15 & -0.5 & 10.7 & 17.5 & 22.5 & 5.0 \\
\hline 10 & 5 & 20.4 & 19.6 & -3.9 & 1.73 & 1.81 & +4.6 & 8.5 & 17.5 & 21.7 & 4.2 \\
\hline 1 & 5 & 21.0 & 21.3 & +1.4 & 1.09 & 1.07 & -1.8 & 5.2 & 20.0 & 22.5 & 2.5 \\
\hline $1-2$ & 10 & 21.1 & 21.3 & +0.9 & 1.37 & 1.36 & -0.7 & 6.5 & 19.2 & 23.4 & 4.2 \\
\hline $1-3$ & 15 & 20.6 & 20.9 & +1.5 & 1.40 & 1.44 & +2.9 & 6.8 & 18.4 & 23.4 & 5.0 \\
\hline $1-4$ & 20 & 20.4 & 19.2 & -5.9 & 1.92 & 2.25 & +17.2 & 9.4 & 15.0 & 23.4 & 8.4 \\
\hline $1-5$ & 25 & 20.2 & 19.2 & -5.0 & 1.94 & 2.15 & +10.8 & 9.6 & 15.0 & 23.4 & 8.4 \\
\hline $1-6$ & 30 & 20.4 & 19.2 & -5.9 & 1.83 & 2.06 & +12.6 & 9.0 & 15.0 & 23.4 & 8.4 \\
\hline $1-7$ & 35 & 20.3 & 19.2 & -5.4 & 1.72 & 2.00 & +16.3 & 8.5 & 15.0 & 23.4 & 8.4 \\
\hline $1-8$ & 40 & 20.6 & 19.6 & -4.9 & 1.82 & 2.13 & +17.0 & 8.8 & 15.0 & 24.2 & 9.2 \\
\hline $1-9$ & 45 & 20.5 & 19.6 & -4.4 & 1.84 & 2.08 & +13.0 & 9.0 & 15.0 & 24.2 & 9.2 \\
\hline $1-10$ & 50 & 20.5 & 19.6 & -4.4 & 1.81 & 2.04 & +12.7 & 8.8 & 15.0 & 24.2 & 9.2 \\
\hline
\end{tabular}

${ }^{\mathrm{a}}$ All comparisons of SD and EstSD not statistically significant $(\mathrm{P}>0.05)$.

TABLE 4. - Statistical parameters of dataset METRID1 (Williams, 1998), which comprises lengths of spirocysts from a tentacle tip of Metridium senile. All abbreviations for headings as for Table 1. All parameters except $n, \mathrm{CoV}$ and percentage differences in $\mu \mathrm{m}$ (accuracy $\pm 0.83 \mu \mathrm{m})$.

\begin{tabular}{|c|c|c|c|c|c|c|c|c|c|c|c|}
\hline Subset & $\mathrm{n}$ & Mean & EstM & $\%$ diffM & SD & EstSD & $\% \operatorname{diffSD}{ }^{a}$ & $\mathrm{CoV}$ & Min & Max & Range \\
\hline 1 & 5 & 16.4 & 15.9 & -3.0 & 0.75 & 0.69 & -8.0 & 4.6 & 15.1 & 16.7 & 1.6 \\
\hline 2 & 5 & 16.9 & 15.9 & -5.9 & 2.07 & 2.15 & +3.9 & 12.3 & 13.4 & 18.4 & 5.0 \\
\hline 3 & 5 & 12.7 & 12.6 & -0.8 & 2.54 & 2.19 & -13.8 & 20.0 & 10.0 & 15.1 & 5.1 \\
\hline 4 & 5 & 15.2 & 14.2 & -6.6 & 2.24 & 2.15 & -4.0 & 14.7 & 11.7 & 16.7 & 5.0 \\
\hline 5 & 5 & 14.0 & 13.4 & -4.3 & 2.54 & 2.88 & +13.4 & 18.1 & 10.0 & 16.7 & 6.7 \\
\hline 6 & 5 & 14.9 & 14.2 & -4.7 & 1.90 & 2.15 & +13.2 & 12.8 & 11.7 & 16.7 & 5.0 \\
\hline 7 & 5 & $18.4^{\mathrm{b}}$ & 18.0 & -2.2 & 1.77 & 1.76 & -0.6 & 9.6 & 15.9 & 20.0 & 4.1 \\
\hline 8 & 5 & 14.9 & 15.1 & +1.3 & 2.79 & 2.88 & +3.2 & 18.8 & 11.7 & 18.4 & 6.7 \\
\hline 9 & 5 & 14.5 & 14.2 & -2.1 & 2.54 & 2.84 & +11.8 & 17.5 & 10.9 & 17.5 & 6.6 \\
\hline 10 & 5 & 16.0 & 15.9 & -0.6 & 3.04 & 3.57 & +17.4 & 19.0 & 11.7 & 20.0 & 8.3 \\
\hline 1 & 5 & 16.4 & 15.9 & -3.0 & 0.75 & 0.69 & -8.0 & 4.6 & 15.1 & 16.7 & 1.6 \\
\hline $1-2$ & 10 & 16.7 & 15.9 & -4.8 & 1.50 & 1.62 & +8.0 & 9.0 & 13.4 & 18.4 & 5.0 \\
\hline $1-3$ & 15 & 15.3 & 14.2 & -7.2 & 2.64 & 2.42 & -8.3 & 17.2 & 10.0 & 18.4 & 8.4 \\
\hline $1-4$ & 20 & 15.3 & 14.2 & -7.2 & 2.49 & 2.25 & -9.6 & 16.3 & 10.0 & 18.4 & 8.4 \\
\hline $1-5$ & 25 & 15.0 & 14.2 & -5.3 & 2.49 & 2.15 & -13.7 & 16.6 & 10.0 & 18.4 & 8.4 \\
\hline $1-6$ & 30 & 15.0 & 14.2 & -5.3 & 2.37 & 2.06 & -13.1 & 15.8 & 10.0 & 18.4 & 8.4 \\
\hline $1-7$ & 35 & 15.5 & 15.0 & -3.2 & 2.57 & 2.38 & -7.4 & 16.6 & 10.0 & 20.0 & 10.0 \\
\hline $1-8$ & 40 & 15.4 & 15.0 & -2.6 & 2.57 & 2.31 & -10.1 & 16.7 & 10.0 & 20.0 & 10.0 \\
\hline $1-9$ & 45 & 15.3 & 15.0 & -2.0 & 2.56 & 2.27 & -11.3 & 16.7 & 10.0 & 20.0 & 10.0 \\
\hline $1-10$ & 50 & 15.4 & 15.0 & -2.6 & 2.59 & 2.22 & -14.3 & 16.8 & 10.0 & 20.0 & 10.0 \\
\hline
\end{tabular}

${ }^{a}$ All comparisons of SD and EstSD not statistically significant $(\mathrm{P}>0.05)$.

b Statistically significantly different $(\mathrm{P}<0.05)$ from mean of whole dataset $(15.4 \mu \mathrm{m})$.

the observed ranges and extreme values of datasets NEMATO1, HALIP1, SAGART1, METRID1, CEREUS1, SAGART6, SAGART7, ANTHO1 and URTIC3, respectively. With regard to the accumulated subsets $(n=5-50)$ of each dataset, the standard deviations of the smaller subsets were somewhat variable, but they stabilized, as did the means, at 10-
20 observations; however, the ranges stabilized at 20-40 observations, which tends to confirm the theoretical expectation.

Since the individual $(n=5)$ and accumulated ( $n$ $=5-50)$ subsets of data are independent and random, they can be used to test the predictive values of Lindley and Miller's (1964) Table 6 and Snedecor 
TABLE 5. - Statistical parameters of dataset CEREUS1 (Williams, 1998), which comprises lengths of microbasic $p$-mastigophore nematocysts from a tentacle tip of Cereus pedunculatus. All abbreviations for headings as for Table 1 . All parameters except $n$, CoV and percentage differences in $\mu \mathrm{m}$ (accuracy $\pm 0.83 \mu \mathrm{m}$ ). There were no statistically significant differences between the means of any independent subsets of 5 and the overall mean $(19.5 \mu \mathrm{m})$ of the whole dataset.

\begin{tabular}{|c|c|c|c|c|c|c|c|c|c|c|c|}
\hline Subset & $\mathrm{n}$ & Mean & EstM & $\%$ diffM & $\mathrm{SD}$ & EstSD & $\% \operatorname{diffSD}^{\mathrm{a}}$ & $\mathrm{CoV}$ & Min & Max & Range \\
\hline 1 & 5 & 19.0 & 18.4 & -3.2 & 1.49 & 1.42 & -4.7 & 7.9 & 16.7 & 20.0 & 3.3 \\
\hline 2 & 5 & 20.4 & 20.5 & +0.5 & 0.46 & 0.39 & -15.2 & 2.2 & 20.0 & 20.9 & 0.9 \\
\hline 3 & 5 & 20.2 & 20.5 & +1.5 & 0.92 & 1.07 & +16.3 & 4.5 & 19.2 & 21.7 & 2.5 \\
\hline 4 & 5 & 19.7 & 19.7 & 0.0 & 0.95 & 1.07 & +12.6 & 4.8 & 18.4 & 20.9 & 2.5 \\
\hline 5 & 5 & 19.4 & 19.2 & -1.0 & 1.37 & 1.46 & +6.6 & 7.1 & 17.5 & 20.9 & 3.4 \\
\hline 6 & 5 & 19.4 & 19.2 & -1.0 & 0.70 & 0.69 & -1.4 & 3.6 & 18.4 & 20.0 & 1.6 \\
\hline 7 & 5 & 19.5 & 19.6 & +0.5 & 0.46 & 0.34 & -26.1 & 2.4 & 19.2 & 20.0 & 0.8 \\
\hline 8 & 5 & 19.7 & 20.0 & +1.5 & 2.01 & 2.15 & +7.0 & 10.2 & 17.5 & 22.5 & 5.0 \\
\hline 9 & 5 & 19.2 & 19.2 & 0.0 & 1.67 & 1.46 & -12.6 & 8.7 & 17.5 & 20.9 & 3.4 \\
\hline 10 & 5 & 18.9 & 18.4 & -2.6 & 1.40 & 1.42 & +1.4 & 7.4 & 16.7 & 20.0 & 3.3 \\
\hline 1 & 5 & 19.0 & 18.4 & -3.2 & 1.49 & 1.42 & -4.7 & 7.9 & 16.7 & 20.0 & 3.3 \\
\hline $1-2$ & 10 & 19.7 & 18.8 & -4.6 & 1.26 & 1.36 & +7.9 & 6.4 & 16.7 & 20.9 & 4.2 \\
\hline $1-3$ & 15 & 19.9 & 19.2 & -3.5 & 1.15 & 1.44 & +25.2 & 5.8 & 16.7 & 21.7 & 5.0 \\
\hline $1-4$ & 20 & 19.8 & 19.2 & -3.0 & 1.08 & 1.34 & +24.1 & 5.4 & 16.7 & 21.7 & 5.0 \\
\hline $1-5$ & 25 & 19.7 & 19.2 & -2.5 & 1.13 & 1.28 & +13.3 & 5.7 & 16.7 & 21.7 & 5.0 \\
\hline $1-6$ & 30 & 19.7 & 19.2 & -2.5 & 1.07 & 1.23 & +15.0 & 5.4 & 16.7 & 21.7 & 5.0 \\
\hline $1-7$ & 35 & 19.7 & 19.2 & -2.5 & 1.00 & 1.19 & +19.0 & 5.1 & 16.7 & 21.7 & 5.0 \\
\hline $1-8$ & 40 & 19.7 & 19.6 & -0.5 & 1.13 & 1.34 & +18.6 & 5.7 & 16.7 & 22.5 & 5.8 \\
\hline $1-9$ & 45 & 19.6 & 19.6 & 0.0 & 1.19 & 1.31 & +10.1 & 6.1 & 16.7 & 22.5 & 5.8 \\
\hline $1-10$ & 50 & 19.5 & 19.6 & +0.5 & 1.22 & 1.29 & +5.7 & 6.2 & 16.7 & 22.5 & 5.8 \\
\hline
\end{tabular}

${ }^{a}$ All comparisons of SD and EstSD not statistically significant $(\mathrm{P}>0.05)$.

TABLE 6. - Statistical parameters of dataset SAGART6 (Williams, 1998), which comprises lengths of basitrich nematocysts from the end of an acontium of Sagartia elegans. All abbreviations for headings as for Table 1 . All parameters except $n, \mathrm{CoV}$ and percentage differences in $\mu \mathrm{m}($ accuracy $\pm 0.46 \mu \mathrm{m})$. There were no statistically significant differences between the means of any independent subsets of 5 and the overall mean $(30.5 \mathrm{um})$ of the whole dataset.

\begin{tabular}{|c|c|c|c|c|c|c|c|c|c|c|c|}
\hline Subset & $\mathrm{n}$ & Mean & EstM & $\%$ diffM & SD & EstSD & $\% \operatorname{diffSD}{ }^{a}$ & $\mathrm{CoV}$ & Min & Max & Range \\
\hline 1 & 5 & 30.0 & 29.9 & -0.3 & 2.22 & 1.98 & -10.8 & 7.4 & 27.6 & 32.2 & 4.6 \\
\hline 2 & 5 & 28.7 & 29.5 & +2.8 & 1.51 & 1.59 & $\begin{array}{l}+5.3 \\
\end{array}$ & 5.3 & 27.6 & 31.3 & 3.7 \\
\hline 3 & 5 & 29.1 & 30.0 & +3.1 & 3.30 & 2.79 & -15.5 & 11.3 & 26.7 & 33.2 & 6.5 \\
\hline 4 & 5 & 30.4 & 30.9 & +1.6 & 3.33 & 3.57 & +7.2 & 10.9 & 26.7 & 35.0 & 8.3 \\
\hline 5 & 5 & 30.9 & 31.4 & +1.6 & 1.40 & 1.59 & +13.6 & 4.5 & 29.5 & 33.2 & 3.7 \\
\hline 6 & 5 & 30.9 & 29.9 & -3.2 & 1.91 & 1.98 & +3.7 & 6.2 & 27.6 & 32.2 & 4.6 \\
\hline 7 & 5 & 32.1 & 32.3 & +0.6 & 0.77 & 0.82 & +6.5 & 2.4 & 31.3 & 33.2 & 1.9 \\
\hline 8 & 5 & 29.1 & 29.5 & +1.4 & 3.09 & 3.18 & +2.9 & 10.6 & 25.8 & 33.2 & 7.4 \\
\hline 9 & 5 & 31.9 & 30.9 & -3.1 & 2.49 & 2.79 & +12.0 & 7.8 & 27.6 & 34.1 & 6.5 \\
\hline 10 & 5 & 31.3 & 31.4 & +0.3 & 2.35 & 2.36 & +0.4 & 7.5 & 28.6 & 34.1 & 5.5 \\
\hline 1 & 5 & 30.0 & 29.9 & -0.3 & 2.22 & 1.98 & -10.8 & 7.4 & 27.6 & 32.2 & 4.6 \\
\hline $1-2$ & 10 & 29.4 & 29.9 & +1.7 & 1.91 & 1.49 & -22.0 & 6.5 & 27.6 & 32.2 & 4.6 \\
\hline $1-3$ & 15 & 29.3 & 30.0 & +2.4 & 2.34 & 1.88 & -19.7 & 8.0 & 26.7 & 33.2 & 6.5 \\
\hline $1-4$ & 20 & 29.6 & 30.9 & +4.4 & 2.57 & 2.22 & -13.6 & 8.7 & 26.7 & 35.0 & 8.3 \\
\hline $1-5$ & 25 & 29.8 & 30.9 & +3.7 & 2.42 & 2.13 & -12.0 & 8.1 & 26.7 & 35.0 & 8.3 \\
\hline $1-6$ & 30 & 30.0 & 30.9 & +3.0 & 2.35 & 2.03 & -13.6 & 7.8 & 26.7 & 35.0 & 8.3 \\
\hline $1-7$ & 35 & 30.3 & 30.9 & +2.0 & 2.30 & 1.98 & -13.9 & 7.6 & 26.7 & 35.0 & 8.3 \\
\hline $1-8$ & 40 & 30.2 & 30.4 & +0.7 & 2.40 & 2.13 & -11.3 & 8.0 & 25.8 & 35.0 & 9.2 \\
\hline $1-9$ & 45 & 30.4 & 30.4 & 0.0 & 2.44 & 2.08 & -14.8 & 8.0 & 25.8 & 35.0 & 9.2 \\
\hline $1-10$ & 50 & 30.5 & 30.4 & -0.3 & 2.43 & 2.04 & -16.0 & 8.0 & 25.8 & 35.0 & 9.2 \\
\hline
\end{tabular}

all comparisons of SD and EstSD not statistically significant $(\mathrm{P}>0.05)$.

and Cochran's (1967) Table 2.4.1. It is apparent from Tables 1-9 herein that there is fairly good agreement between the calculated sample standard deviations (SD) and those estimated (EstSD) from the sample ranges. In 79/163 cases ( $c a 49 \%$ ), the difference ( $\%$ diffSD) between the calculated and estimated standard deviations was $\pm \leq 10 \%$, and in $155 / 163$ cases ( $c a 95 \%)$, it was $\pm \leq 20 \%$. In each of the 163 comparisons, a two-tailed F-test revealed no statistically significant difference between the variances derived from the calculated and the estimated standard deviations $(\mathrm{P}>0.05)$. It is, therefore, con- 
TABLE 7. - Statistical parameters of dataset SAGART7 (Williams, 1998), which comprises lengths of basitrich nematocysts from the end of an acontium of Sagartia troglodytes. All abbreviations for headings as for Table 1 . All parameters except $n$, CoV and percentage differences in $\mu \mathrm{m}$ (accuracy $\pm 0.46 \mu \mathrm{m}$ ). There were no statistically significant differences between the means of any independent subsets of 5 and the overall mean $(15.4 \mu \mathrm{m})$ of the whole dataset.

\begin{tabular}{|c|c|c|c|c|c|c|c|c|c|c|c|}
\hline Subset & $\mathrm{n}$ & Mean & EstM & $\%$ diffM & SD & EstSD & $\%$ diffSD ${ }^{a}$ & $\mathrm{CoV}$ & Min & Max & Range \\
\hline 1 & 5 & 14.9 & 14.8 & -0.7 & 1.37 & 1.59 & +16.1 & 9.2 & 12.9 & 16.6 & 3.7 \\
\hline 2 & 5 & 15.7 & 15.7 & 0.0 & 0.00 & 0.00 & 0.0 & 0.0 & 15.7 & 15.7 & 0.0 \\
\hline 3 & 5 & 15.2 & 15.7 & +3.3 & 0.80 & 0.82 & +2.5 & 5.2 & 14.7 & 16.6 & 1.9 \\
\hline 4 & 5 & 16.1 & 16.1 & 0.0 & 1.03 & 1.20 & +16.5 & 6.4 & 14.7 & 17.5 & 2.8 \\
\hline 5 & 5 & 14.7 & 15.2 & +3.4 & 1.16 & 1.20 & +3.4 & 7.9 & 13.8 & 16.6 & 2.8 \\
\hline 6 & 5 & 16.1 & 16.1 & 0.0 & 1.66 & 1.98 & +19.3 & 10.3 & 13.8 & 18.4 & 4.6 \\
\hline 7 & 5 & 15.7 & 16.1 & +2.5 & 1.84 & 1.98 & +7.6 & 11.7 & 13.8 & 18.4 & 4.6 \\
\hline 8 & 5 & 15.1 & 15.0 & -0.7 & 0.89 & 0.99 & +11.2 & 5.9 & 13.8 & 16.1 & 2.3 \\
\hline 1 & 5 & 14.9 & 14.8 & -0.7 & 1.37 & 1.59 & +16.1 & 9.2 & 12.9 & 16.6 & 3.7 \\
\hline $1-2$ & 10 & 15.3 & 14.8 & -3.3 & 0.99 & 1.20 & +21.2 & 6.5 & 12.9 & 16.6 & 3.7 \\
\hline $1-3$ & 15 & 15.3 & 14.8 & -3.3 & 0.90 & 1.07 & +18.9 & 5.9 & 12.9 & 16.6 & 3.7 \\
\hline $1-4$ & 20 & 15.5 & 15.2 & -1.9 & 0.98 & 1.23 & +25.5 & 6.4 & 12.9 & 17.5 & 4.6 \\
\hline $1-5$ & 25 & 15.3 & 15.2 & -0.7 & 1.04 & 1.18 & +13.5 & 6.8 & 12.9 & 17.5 & 4.6 \\
\hline $1-6$ & 30 & 15.5 & 15.7 & +1.3 & 1.17 & 1.35 & +15.4 & 7.6 & 12.9 & 18.4 & 5.5 \\
\hline $1-7$ & 35 & 15.5 & 15.7 & +1.3 & 1.25 & 1.31 & +4.8 & 8.1 & 12.9 & 18.4 & 5.5 \\
\hline $1-8$ & 40 & 15.4 & 15.7 & +1.9 & 1.21 & 1.27 & +5.0 & 7.9 & 12.9 & 18.4 & 5.5 \\
\hline
\end{tabular}

a All comparisons of SD and EstSD not statistically significant $(\mathrm{P}>0.05)$.

TABLE 8. - Statistical parameters of dataset ANTHO1 (Williams, 1998), which comprises lengths of basitrich nematocysts from a tentacle tip of Anthopleura thallia. All abbreviations for headings as for Table 1. All parameters except $n$, CoV and percentage differences in $\mu \mathrm{m}$ (accuracy $\pm 0.46 \mu \mathrm{m})$. There were no statistically significant differences between the means of any independent subsets of 5 and the overall mean $(15.5 \mu \mathrm{m})$ of the whole dataset.

\begin{tabular}{|c|c|c|c|c|c|c|c|c|c|c|c|}
\hline Subset & $\mathrm{n}$ & Mean & EstM & $\%$ diffM & SD & EstSD & $\% \operatorname{diffSD}{ }^{a}$ & $\mathrm{CoV}$ & Min & $\operatorname{Max}$ & Range \\
\hline 1 & 5 & 15.5 & 15.2 & -1.9 & 0.41 & 0.43 & +4.9 & 2.7 & 14.7 & 15.7 & 1.0 \\
\hline 2 & 5 & 16.9 & 17.1 & +1.2 & 1.05 & 1.16 & +10.5 & 6.2 & 15.7 & 18.4 & 2.7 \\
\hline 3 & 5 & 15.3 & 15.9 & +3.9 & 1.58 & 1.81 & +14.6 & 10.3 & 13.8 & 18.0 & 4.2 \\
\hline 4 & 5 & 14.9 & 15.0 & +0.7 & 1.33 & 1.38 & $\begin{array}{r}+3.8 \\
\end{array}$ & 8.9 & 13.4 & 16.6 & 3.2 \\
\hline 5 & 5 & 14.6 & 14.5 & -0.7 & 0.53 & 0.60 & +13.2 & 3.6 & 13.8 & 15.2 & 1.4 \\
\hline 6 & 5 & 16.0 & 15.7 & -1.9 & 1.40 & 1.59 & +13.6 & 8.7 & 13.8 & 17.5 & 3.7 \\
\hline 7 & 5 & 15.0 & 14.8 & -1.3 & 0.77 & 0.82 & +6.5 & 5.1 & 13.8 & 15.7 & 1.9 \\
\hline 8 & 5 & 15.5 & 15.2 & -1.9 & 1.20 & 1.20 & 0.0 & 7.7 & 13.8 & 16.6 & 2.8 \\
\hline 1 & 5 & 15.5 & 15.2 & -1.9 & 0.41 & 0.43 & +4.9 & 2.7 & 14.7 & 15.7 & 1.0 \\
\hline $1-2$ & 10 & 16.2 & 16.6 & +2.5 & 1.08 & 1.20 & +11.1 & 6.7 & 14.7 & 18.4 & 3.7 \\
\hline $1-3$ & 15 & 15.9 & 16.1 & +1.3 & 1.29 & 1.33 & +3.1 & 8.1 & 13.8 & 18.4 & 4.6 \\
\hline $1-4$ & 20 & 15.7 & 15.9 & +1.3 & 1.34 & 1.34 & 0.0 & 8.5 & 13.4 & 18.4 & 5.0 \\
\hline $1-5$ & 25 & 15.4 & 15.9 & +3.2 & 1.29 & 1.28 & -0.8 & 8.4 & 13.4 & 18.4 & 5.0 \\
\hline $1-6$ & 30 & 15.5 & 15.9 & +2.6 & 1.30 & 1.23 & -5.4 & 8.4 & 13.4 & 18.4 & 5.0 \\
\hline $1-7$ & 35 & 15.5 & 15.9 & +2.6 & 1.25 & 1.19 & -4.8 & 8.0 & 13.4 & 18.4 & 5.0 \\
\hline $1-8$ & 40 & 15.5 & 15.9 & +2.6 & 1.23 & 1.16 & -5.7 & 7.9 & 13.4 & 18.4 & 5.0 \\
\hline
\end{tabular}

${ }^{a}$ All comparisons of SD and EstSD not statistically significant $(\mathrm{P}>0.05)$.

cluded that the predictive values of tables for the estimation of a standard deviation from an observed sample range are satisfactory for homogeneous populations of cnida lengths, at least if the data have been sampled randomly.

However, comparison of the calculated and estimated standard deviations of a known heterogeneous population such as SAGETON1 (Table 11) revealed a statistically significant difference $(\mathrm{P}<0.05)$, because the sample was not normally distributed. For this reason, in other publications, if data have been pooled or samples have been con- founded, it is more difficult to obtain reliable estimates of standard deviations from sample ranges. Such cases are discussed further in Appendix I.

\section{The coefficient of variation and its interpretation}

The standard deviation and variance of a sample are absolute measures of dispersion and, although valuable in statistical analyses, they do not make possible direct comparisons of the dispersions of samples with different means. In order to achieve this objective, the coefficient of variation $(\mathrm{CoV})$ is 
TABLE 9. - Statistical parameters of dataset URTIC3 (Williams, 1998), which comprises lengths of basitrich nematocysts from just above the limbus of Urticina eques. All abbreviations for headings as for Table 1 . All parameters except $n$, CoV and percentage differences in $\mu m$ (accuracy $\pm 0.46 \mu \mathrm{m})$. There were no statistically significant differences between the means of any independent subsets of 5 and the overall mean $(19.5 \mu \mathrm{m})$ of the whole dataset.

\begin{tabular}{|c|c|c|c|c|c|c|c|c|c|c|c|}
\hline Subset & $\mathrm{n}$ & Mean & EstM & $\%$ diffM & $\mathrm{SD}$ & EstSD & $\% \operatorname{diffSD}{ }^{a}$ & $\mathrm{CoV}$ & Min & $\operatorname{Max}$ & Range \\
\hline 1 & 5 & 19.6 & 19.6 & 0.0 & 0.84 & 0.99 & +17.9 & 4.3 & 18.4 & 20.7 & 2.3 \\
\hline 2 & 5 & 18.8 & 18.9 & +0.5 & 0.76 & 0.77 & +1.3 & 4.0 & 18.0 & 19.8 & 1.8 \\
\hline 3 & 5 & 19.2 & 19.1 & -0.5 & 0.53 & 0.60 & +13.2 & 2.8 & 18.4 & 19.8 & 1.4 \\
\hline 4 & 5 & 19.8 & 19.4 & -2.0 & 0.80 & 0.82 & +2.5 & 4.0 & 18.4 & 20.3 & 1.9 \\
\hline 5 & 5 & 19.7 & 19.8 & +0.5 & 0.39 & 0.43 & +10.3 & 2.0 & 19.3 & 20.3 & 1.0 \\
\hline 6 & 5 & 19.5 & 19.4 & -0.5 & 0.70 & 0.82 & +17.1 & 3.6 & 18.4 & 20.3 & 1.9 \\
\hline 7 & 5 & 19.3 & 19.1 & -1.0 & 0.50 & 0.60 & +20.0 & 2.6 & 18.4 & 19.8 & 1.4 \\
\hline 8 & 5 & 19.9 & 20.5 & +3.0 & 1.36 & 1.38 & +1.5 & 6.8 & 18.9 & 22.1 & 3.2 \\
\hline 9 & 5 & 20.3 & 20.3 & 0.0 & 0.33 & 0.39 & +18.2 & 1.6 & 19.8 & 20.7 & 0.9 \\
\hline 10 & 5 & 19.1 & 19.2 & +0.5 & 0.90 & 0.99 & +10.0 & 4.7 & 18.0 & 20.3 & 2.3 \\
\hline 1 & 5 & 19.6 & 19.6 & 0.0 & 0.84 & 0.99 & +17.9 & 4.3 & 18.4 & 20.7 & 2.3 \\
\hline $1-2$ & 10 & 19.2 & 19.4 & +1.0 & 0.87 & 0.88 & +1.1 & 4.5 & 18.0 & 20.7 & 2.7 \\
\hline $1-3$ & 15 & 19.2 & 19.4 & +1.0 & 0.75 & 0.78 & +4.0 & 3.9 & 18.0 & 20.7 & 2.7 \\
\hline $1-4$ & 20 & 19.3 & 19.4 & +0.5 & 0.79 & 0.72 & -8.9 & 4.1 & 18.0 & 20.7 & 2.7 \\
\hline $1-5$ & 25 & 19.4 & 19.4 & 0.0 & 0.74 & 0.69 & -6.8 & 3.8 & 18.0 & 20.7 & 2.7 \\
\hline $1-6$ & 30 & 19.4 & 19.4 & 0.0 & 0.72 & 0.66 & -8.3 & 3.7 & 18.0 & 20.7 & 2.7 \\
\hline $1-7$ & 35 & 19.4 & 19.4 & 0.0 & 0.69 & 0.64 & -7.2 & 3.6 & 18.0 & 20.7 & 2.7 \\
\hline $1-8$ & 40 & 19.5 & 20.1 & +3.1 & 0.79 & 0.95 & +20.3 & 4.1 & 18.0 & 22.1 & 4.1 \\
\hline $1-9$ & 45 & 19.6 & 20.1 & +2.6 & 0.79 & 0.93 & +17.7 & 4.0 & 18.0 & 22.1 & 4.1 \\
\hline $1-10$ & 50 & 19.5 & 20.1 & +3.1 & 0.81 & 0.91 & +12.3 & 4.2 & 18.0 & 22.1 & 4.1 \\
\hline
\end{tabular}

${ }^{a}$ All comparisons of SD and EstSD not statistically significant $(\mathrm{P}>0.05)$.

the most useful measure. Unlike the standard deviation and variance, the $\mathrm{CoV}$ does not have an absolute value nor a unit of measurement; it is a quotient expressed as a percentage.

According to Simpson et al. (1960), most CoVs of linear dimensions of anatomical features tend to fall between 4 and 10\%. Much lower values usually indicate that the sample is not large enough to reveal the true variability, and much higher values usually indicate a heterogeneous sample. These general observations of Simpson et al. (1960) are based on measurements of mammalian anatomical features, but they appear to hold good also for the data presented herein on actiniarian cnidae.

For reasonably large samples, a test for the significance of a difference between two CoVs is provided by calculating a $c$ value, as follows (Woolf, 1968):

$$
c=\frac{\left(\mathrm{CoV}_{1}-\mathrm{CoV}_{2}\right)}{\sqrt{\left(\mathrm{SE} \mathrm{CoV}_{1}\right)^{2}+\left(\mathrm{SE} \mathrm{CoV}_{2}\right)^{2}}}
$$

TABLE 10. - Coefficients of variation (CoVs) of data subsets extracted from Tables 1-9.

\begin{tabular}{|c|c|c|c|c|}
\hline Table number & Dataset & Cnida type & Subset sizes & Range of CoVs \\
\hline 1 & NEMATO1 & Basitrich & 5 & $5.7-11.2$ \\
\hline 1 & NEMATO1 & Basitrich & $10-50$ & $6.8-8.8$ \\
\hline 2 & HALIP1 & Microbasic amastigophore & 5 & $0.0-18.6$ \\
\hline 2 & HALIP1 & Microbasic amastigophore & $10-50$ & $12.5-16.4$ \\
\hline 3 & SAGART1 & Basitrich & 5 & $3.5-16.0$ \\
\hline 3 & SAGART1 & Basitrich & $10-50$ & $6.5-9.6$ \\
\hline 4 & METRID1 & Spirocyst & 5 & $4.6-20.0$ \\
\hline 4 & METRID1 & Spirocyst & $10-50$ & $9.0-17.2$ \\
\hline 5 & CEREUS1 & Microbasic $p$-mastigophore & 5 & $2.2-10.2$ \\
\hline 5 & CEREUS1 & Microbasic $p$-mastigophore & $10-50$ & $5.1-6.4$ \\
\hline 6 & SAGART6 & Basitrich & 5 & $2.4-11.3$ \\
\hline 6 & SAGART6 & Basitrich & $10-50$ & $6.5-8.7$ \\
\hline 7 & SAGART7 & Basitrich & 5 & $0.0-11.7$ \\
\hline 7 & SAGART7 & Basitrich & $10-40$ & $6.4-8.1$ \\
\hline 8 & ANTHO1 & Basitrich & 5 & $2.7-10.3$ \\
\hline 8 & ANTHO1 & Basitrich & $10-40$ & $6.7-8.5$ \\
\hline 9 & URTIC3 & Basitrich & 5 & $1.6-6.8$ \\
\hline 9 & URTIC3 & Basitrich & $10-50$ & $3.6-4.5$ \\
\hline
\end{tabular}


The SE CoV (standard error of a CoV) may be obtained by dividing the $\mathrm{CoV}$ by the square root of $2 n$ (Woolf, 1968). A probability table for $c$ is provided by Woolf (1968: Table II). The 95\% confidence limits of a $\mathrm{CoV}$ are given by:

$$
\mathrm{CoV} \pm 1.96(\mathrm{SE} \mathrm{CoV})
$$

The CoVs of the subsets of data from Tables 1-9 are summarized in Table 10. For all nine tables of demonstrably homogeneous data (Williams, 1996, 1998), the range of CoVs was greater for the 8 or 10 independent subsets of 5 observations than for the accumulated subsets of 10 to 40 or 50 observations. This is in accord with the fact that both the means and standard deviations of each dataset were stabilized when subsets included at least 10 to 20 observations (Williams, 1996, 1998). Furthermore, the majority of $\mathrm{CoVs}$ for the accumulated subsets fell between 4 and $10 \%$, which is in agreement with the generalization of Simpson et al. (1960).

Interestingly, the example of the spirocysts (METRID1) of Metridium senile (Table 4), in which rather higher CoVs (9.0-17.2\%) were observed for the accumulated subsets, supports the usual reticence of researchers to employ this cnida type as a taxonomic character, because of its generally greater variability in size than most other cnidae. A series of $c$-tests (Woolf, 1968) showed that the $\mathrm{CoV}$ of dataset METRID1 (Table 4) was statistically significantly greater $(\mathrm{P}<0.001)$ than those of NEMATO1 (Table 1), SAGART1 (Table 3), CEREUS1 (Table 5), SAGART6 (Table 6), SAGART7 (Table 7), ANTHO1 (Table 8) and URTIC3 (Table 9), viz., 16.8 compared with $7.9,8.8,6.2,8.0,7.9,7.9$ and 4.2 , respectively.
The CoVs (12.5-16.4\%) of the accumulated subsets of microbasic amastigophores of Haliplanella lineata (Table 2) may also simply indicate a greater than usual variability of this particular nematocyst type, but it is worth bearing in mind that this is a type the status of which is somewhat controversial. It has been suggested by Cutress (1955) that microbasic amastigophores are really $p$-mastigophores, but Hand (1956) and Williams (1975) maintained them as separate types in $H$. lineata $(=H$. luciae $)$. As it is not easy to distinguish them reliably when undischarged, it might be considered whether the dataset HALIP1 (Table 2) is heterogeneous, since amastigophores and $p$-mastigophores have both been recorded from the tentacles of H. lineata (Hand, 1956; Williams, 1975). However, it is concluded that heterogeneity of HALIP1 is unlikely because, regardless of whether these two nominal types of cnida are morphologically distinct (see England, 1991 for discussion), the combination of the nematocyst measurements recorded separately as amastigophores and $p$-mastigophores in catch-tentacles by Williams (1975: Table 2) would have created a definite bimodal frequency distribution of non-overlapping size ranges. This is certainly not the case with the present dataset (HALIP1), as confirmed by a dotplot (Williams, 1996). A series of $c$ tests (Woolf, 1968) showed that the CoV of dataset HALIP1 (Table 2) was, nevertheless, statistically significantly greater $(\mathrm{P}<0.01)$ than those of NEMATO1 (Table 1), SAGART1 (Table 3), CEREUS1 (Table 5), SAGART6 (Table 6), SAGART7 (Table 7), ANTHO1 (Table 8) and URTIC3 (Table 9), viz., 13.4 compared with 7.9, 8.8, 6.2, 8.0, 7.9, 7.9 and 4.2, respectively.

The CoVs of the definitely heterogeneous dataset SAGETON1 (Table 11) are, as expected, very much higher than those even of METRID1 (Table 4) and

TABLE 11. - Statistical parameters of dataset SAGETON1 (Williams, 1996), which comprises lengths of basitrich nematocysts of two size ranges from just above the limbus of Sagartiogeton laceratus. All abbreviations for headings as for Table 1 . All parameters except $n$, CoV and percentage differences in $\mu \mathrm{m}$ (accuracy $\pm 0.46 \mu \mathrm{m})$.

\begin{tabular}{|c|c|c|c|c|c|c|c|c|c|c|c|}
\hline Subset & $\mathrm{n}$ & Mean & EstM & $\%$ diffM & SD & EstSD & $\%$ diffSD & $\mathrm{CoV}$ & Min & Max & Range \\
\hline 1 & 5 & 16.7 & 16.6 & -0.6 & 0.82 & 0.77 & -6.1 & 4.9 & 15.7 & 17.5 & 1.8 \\
\hline 2 & 5 & 14.3 & 13.4 & -6.3 & 3.09 & 3.57 & +15.5 & 21.6 & 9.2 & 17.5 & 8.3 \\
\hline 3 & 5 & 13.4 & 13.4 & 0.0 & 3.70 & 2.79 & -24.6 & 27.6 & 10.1 & 16.6 & 6.5 \\
\hline 4 & 5 & 17.6 & 17.5 & -0.6 & 0.68 & 0.77 & +13.2 & 3.9 & 16.6 & 18.4 & 1.8 \\
\hline 5 & 5 & 15.7 & 13.4 & -14.6 & 3.63 & 3.57 & -1.6 & 23.1 & 9.2 & 17.5 & 8.3 \\
\hline 6 & 5 & 16.0 & 14.5 & -9.4 & 3.70 & 4.13 & +11.6 & 23.1 & 9.7 & 19.3 & 9.6 \\
\hline 7 & 5 & 15.3 & 13.4 & -12.4 & 3.44 & 3.57 & +3.8 & 22.5 & 9.2 & 17.5 & 8.3 \\
\hline 8 & 5 & 14.0 & 13.6 & -2.9 & 4.63 & 4.17 & -9.9 & 33.1 & 8.7 & 18.4 & 9.7 \\
\hline 9 & 5 & 15.4 & 13.4 & -13.0 & 3.47 & 3.57 & +2.9 & 22.5 & 9.2 & 17.5 & 8.3 \\
\hline 10 & 5 & 13.0 & 13.1 & +0.8 & 3.83 & 3.78 & -1.3 & 29.5 & 8.7 & 17.5 & 8.8 \\
\hline $1-10$ & 50 & 15.1 & 14.0 & -7.3 & 3.32 & 2.35 & $-29.2^{\mathrm{a}}$ & 22.0 & 8.7 & 19.3 & 10.6 \\
\hline
\end{tabular}

a Comparison of SD and EstSD statistically significant $(\mathrm{P}<0.05)$. 
TABLE 12. - Statistical parameters of two subpopulations (L and S) of dataset SAGETON1 (see Table 11) with a bimodal distribution (L and $\mathrm{S})$. All abbreviations for headings as for Table 1 . All parameters except $n, \mathrm{CoV}$ and percentage differences in $\mu \mathrm{m}$ (accuracy $\pm 0.46 \mu \mathrm{m})$.

\begin{tabular}{|c|c|c|c|c|c|c|c|c|c|c|c|}
\hline Subset & $\mathrm{n}$ & Mean & EstM & $\%$ diffM & $\mathrm{SD}$ & EstSD & $\%$ diffSD & $\mathrm{CoV}$ & Min & Max & Range \\
\hline $\mathrm{L}$ & 39 & 16.8 & 16.8 & 0.0 & 1.08 & 1.16 & +7.4 & 6.4 & 14.3 & 19.3 & 5.0 \\
\hline $\mathrm{S}$ & 11 & 9.2 & 9.4 & +2.2 & 0.41 & 0.44 & +7.3 & 4.5 & 8.7 & 10.1 & 1.4 \\
\hline
\end{tabular}

HALIP1 (Table 2), the whole dataset of 50 observations having a $\mathrm{CoV}$ of 22.0. Furthermore, the calculated and estimated standard deviations have already been shown to be statistically significantly different $(\mathrm{P}<0.05)$, as expected for a non-normal distribution. Most of the subsets of SAGETON1 were heterogeneous, the only homogeneous ones being subsets 1 and 4 with CoVs of 4.9 and 3.9, respectively; the $\mathrm{CoVs}$ of the other subsets ranged from 21.6 to 33.1 (Table 11). The bimodal dotplot of dataset SAGETON1 clearly revealed that it comprised two size ranges of basitrichs (Williams, 1996: Fig. 4a) and when, from the dotplot, they were separated into large (L) and small (S) subpopulations (Table 12), their respective CoVs were only 6.4 and 4.5 . This demonstrates well the utility of the $\mathrm{CoV}$ as a clue for detecting heterogeneity in cnida samples.

Dotplots should always be constructed to help in the interpretation of frequency distributions (Williams, 1996). The use of CoVs without dotplots and other evidence would have misleadingly indicated possible heterogeneity of datasets METRID1 (Table 4) and HALIP1 (Table 2).

\section{The observed sample range and its interpretation}

Simpson (1980: 180), discussing range as a zoological character, stated "The sample range is (for practical purposes) always smaller than the population range and it never tends to have the same value... the sample range seldom tends to be over half as large as the population range. Moreover, the tendency is different in samples of different sizes so that the direct comparison of ranges derived from different numbers of observations is incorrect and usually grossly misleading, despite its widespread use." Thus, there is a major flaw in the conventional assumption that slightly overlapping or non-overlapping length extremes of the same cnida type observed in different specimens of anemone indicate that they belong to different species.

The correct approach for comparing ranges is to use an estimate of the maximum likely population range, calculated from each observed sample standard deviation (Simpson, 1980). Ideally, such estimates should be based upon validly collected random data from homogeneous samples, such as those provided by Williams $(1996,1998)$. Sometimes, however, if the observed individual data are not available, the standard deviation may have to be estimated from the observed sample range (see 1) above); this procedure is less reliable if the data do not constitute a random, normally distributed sample. It is also clear that the range is unduly influenced by any single observation that lies well outside the upper or lower limits of the rest of the observations.

\section{The population range: methods of estimation from a standard deviation}

Having calculated a sample standard deviation from the individual data or having estimated it from a sample range, the properties of the normal distribution allow the estimation of the wider population range. If a population range has been estimated from a calculated sample standard deviation, its central point is logically the mean calculated from the same data. However, if the standard deviation has had to be estimated from an observed sample range only, and the original data are not available for the calculation of a mean, the central point should be estimated from the mid-point of the extremes of the observed range, i.e., the median. Occasionally, some authors (e.g., Watzl, 1922; Stephenson, 1929) may have provided the observed sample range extremes with the calculated mean, which may, therefore, be used as the central point of the distribution.

Two ways of estimating a population range are considered here. The first makes use of the properties of a normal distribution and its standard deviation; the second is the more preferable standard population range.

\section{Population range calculated from a sample standard deviation}

Since $99.74 \%$ of the area under a normal distribution curve is bounded by 3 standard deviations on 
each side of the mean (Snedecor and Cochran, 1980), a population range may be calculated as 6 standard deviations. Taking as an example the dataset CEREUS1 of 50 lengths of microbasic $p$ mastigophore nematocysts from Cereus pedunculatus (Table 5), the calculated sample standard deviation is $1.22 \mu \mathrm{m}$ and the mean is $19.5 \mu \mathrm{m}$. Therefore, the range is $6 \times 1.22 \mu \mathrm{m}$ or $7.32 \mu \mathrm{m}$, and the population extremes are $c a 19.5 \pm(3 \times 1.22) \mu \mathrm{m}$ or 15.84-23.16 $\mu \mathrm{m}$. Alternatively, using the standard deviation of $1.29 \mu \mathrm{m}$ estimated from the observed sample range (Table 5), the estimated range would be $7.74 \mu \mathrm{m}$. The estimated mean (median) is 19.6 $\mu \mathrm{m}$ and the population extremes are therefore $c a$ 15.73-23.47 $\mu \mathrm{m}$. These two sets of estimated population extremes, one derived from the sample standard deviation and the other derived from a standard deviation estimated from the observed sample range, are in very close agreement. However, a more preferable estimation of a population range is the standard range described below.

\section{Standard population range calculated from a standard deviation with a standard abundance of 1,000}

A more conservative estimate of a population range than the mean \pm 3 standard deviations described above is the standard range calculated from a standard deviation, adopting 1,000 as a standard abundance (Simpson, 1980: 184-185) (see 3) above). Its great advantage over the observed range is that it tends to have the same value when based on samples from the same population, regardless of the sizes of the samples (Simpson, 1980: 180). Given the calculated or estimated sample standard deviation, a mean population range is estimated by multiplying the standard deviation by the appropriate factor for a sample size of 1,000 (Simpson, 1980: Table $5-2$ ), which is 6.48287. Thus for the dataset CEREUS1 (Table 5), the standard population range using the calculated sample standard deviation is $1.22 \times 6.48287 \mu \mathrm{m}$ or $c a 7.9 \mu \mathrm{m}$; using the standard deviation estimated from the observed range, the standard range is $1.29 \times 6.48287 \mu \mathrm{m}$ or $\mathrm{ca} 8.4 \mu \mathrm{m}$.

As predicted by Simpson (1980), this estimated population range (standard range) considerably exceeds (by $>36 \%$ ) that of the observed sample range, which is only $5.8 \mu \mathrm{m}$ (Table 5). Of course, any estimate of a standard population range is subject to a statistical error. Calculation of a probable maximum value, using one per cent points (99\% confidence limits) (see 4) above), is therefore a wise precaution, and gives the most realistic estimate of all, as shown below.

\section{The $99 \%$ probable maximum value of the standard range, and its estimation from a standard deviation}

The most realistic estimate of a standard population range is the $99 \%$ probable maximum value, which will in most cases obviate the drawing of erroneous conclusions based on a lack of overlap between extremes of observed population ranges of cnidae. Therefore, when calculating a probable maximum standard population range, it is important to estimate the range of values of the greatest standard population range calculated from standard deviations likely to arise from multiple samples drawn from the same population. This is because it cannot be assumed that a sample standard deviation is exactly the same as the population standard deviation, although repeated sampling should give a mean value close to the population standard deviation.

One per cent points of a standard deviation occur at \pm 2.576 times its standard error, i.e., there is only about one chance in a hundred that samples from a given population will differ by more than this amount from the true population value. The standard error of a standard deviation is obtained by dividing the standard deviation by the square root of $2 n$ (Simpson and Roe, 1939).

Following Simpson's (1980: 185) method of calculating a $99 \%$ probable maximum value of a standard range, the appropriate calculations for the example of Cereus pedunculatus (Table 5) are as follows:

$$
\begin{aligned}
& \text { sample size }=50 \\
& \text { standard deviation }=1.22 \mu \mathrm{m} \\
& \text { standard error of } \\
& \text { standard deviation }=1.22 \div \sqrt{2 \times 50}=0.122 \mu \mathrm{m}
\end{aligned}
$$

Therefore, the one per cent points of the standard deviation $=0.122 \times 2.576=0.31 \mu \mathrm{m}$.

Hence, the probable maximum value of population standard deviation $=1.22+0.31=1.53 \mu \mathrm{m}$. The $99 \%$ probable maximum value of mean range in samples of $1,000=1.53 \times 6.48287=9.92 \mu \mathrm{m}$.

Therefore, the extremes of the $99 \%$ probable maximum standard range for dataset CEREUS 1 are $19.5 \pm(9.92 \div 2)=14.5-24.5 \mu \mathrm{m}$. This compares 
with the original observed sample extreme values of 16.7-22.5 $\mu \mathrm{m}$ (Table 5). The observed range in a sample of 50 was $5.8 \mu \mathrm{m}$ (Table 5), or $58.5 \%$ of the $99 \%$ probable maximum value of the mean range $(9.92 \mu \mathrm{m})$ in samples of 1,000 .

\section{Are estimated population ranges of cnida measurements of practical value for taxonomic purposes?}

Statistical or subjective comparisons of the standard deviations, variances and CoVs provide information only about the variabilities of samples. They do not reveal anything about the actual numerical limits of the constituent observations. On the other hand, observed ranges reveal little about the distribution of a sample, but if the extremes are included, the relative spread of the distribution becomes apparent. Unfortunately, there are apparently no valid statistical methods of comparison for ranges and their extremes. What is their objective value, therefore, in taxonomic inference?

\section{Statistical validity of sampling of cnida measurements}

With regard to the central parameter of a normal frequency distribution, the between-sample (same specimen) and between-specimen variations of mean cnida lengths in a sea anemone species are such that classical significance tests are too sensitive and sometimes may lead to the erroneous conclusion that specimens are not conspecific when they are, in fact, of the same species (Williams, 1996, 1998). The common alternative practice of using observed cnida size extremes to distinguish between species (see Fautin, 1988) is also flawed because sample ranges do not represent true population ranges (Simpson, 1980). An example of the derivation of a 99\% probable maximum value of a standard population range from a sample standard deviation has been given above, based on validly collected random data presented herein. This represents the most realistic estimate of a population range.

It is not easy to find examples of observed sample ranges in previously published data that are amenable to rigorous statistical treatment. A frequent problem, even with fairly recent publications, is that various unspecified numbers of cnidae were measured in tissue samples (sometimes several samples of the same tissue type from one specimen) from several different specimens, and only the overall range and number were recorded (e.g., Dunn (1981); Williams (1981); Fautin and Chia (1986); Chintiroglou and den Hartog (1995); Riemann-Zürneck (1997)). Often, no indication of whether sampling was random is given; sometimes, however, some explicit statement indicates that sampling was not random. England (1971, 1987, $1988,1990,1992)$ was almost alone in presenting separate sets of measurements from individual specimens of anemones, but even so, the extremes given were usually combined from several samples of each tissue type, and furthermore the largest and smallest sizes were deliberately selected (see England, 1987). Thus, the data still do not satisfy the criteria of independent, random sampling of a homogeneous population necessary for valid statistical treatment (Williams, 1996).

It is emphasized that the foregoing remarks are not intended to be critical of the work cited, since the authors generally made no explicit statements regarding the statistical or taxonomic values of the cnida size ranges given. These examples are cited simply to demonstrate that in the light of recent research (Williams, 1996, 1998) the data would have certain limitations if used uncritically for statistical purposes in the future.

\section{Are population ranges any better than means of cnida measurements as taxonomic criteria?}

To address this question, some appropriate data (Williams, 1996, 1998) were re-examined. The means of these datasets of cnida lengths from conspecific individuals of several species had already been compared within groups of anemones by analysis of means or within pairs of anemones by $t$ tests. The extremes of the ranges of the same datasets were compared to see if the same conclusions as those drawn from comparisons of the means might be reached.

Three types of range were compared (Tables 1319); the observed sample range, the standard range with standard abundance of 1,000 and the 99\% probable maximum range. For all three ranges, the central point of the distribution in each of these examples was the calculated mean, since the ranges were based on individual, randomly sampled data. For the same reason, the standard range and its $99 \%$ probable maximum were estimated from the calculated standard deviation. Since some discussion of percentage overlaps of distributions of cnida lengths is included here, the methods for their calculation are described in Appendix II. 
TABLE 13. - The observed, standard population and probable maximum ranges of samples of lengths of larger basitrich nematocysts from just above the limbus of Sagartiogeton laceratus. $\mathrm{PDD}=$ pedal disk diameter $(\mathrm{mm}) ; \mathrm{SD}=\mathrm{sample}$ standard deviation. All parameters except $\mathrm{n}$ and PDD in $\mu \mathrm{m}$ (accuracy $\pm 0.46 \mu \mathrm{m})$.

\begin{tabular}{|c|c|c|c|c|c|c|c|c|c|c|}
\hline Dataset & PDD & $\mathrm{n}$ & Mean & SD & $\begin{array}{l}\text { Observed } \\
\text { sample } \\
\text { extremes }\end{array}$ & $\begin{array}{l}\text { Observed } \\
\text { sample } \\
\text { range }\end{array}$ & $\begin{array}{c}\text { Standard } \\
\text { extremes } \\
(\mathrm{n}=1,000)\end{array}$ & $\begin{array}{l}\text { Standard } \\
\text { range } \\
(\mathrm{n}=1,000)\end{array}$ & $\begin{array}{l}99 \% \text { probable } \\
\text { maximum } \\
\text { extremes }\end{array}$ & $\begin{array}{l}99 \% \text { probable } \\
\text { maximum } \\
\text { range }\end{array}$ \\
\hline SAGETON3 & 4 & 43 & 17.3 & 2.45 & $12.9-22.1$ & 9.2 & $9.4-25.2$ & 15.8 & $7.2-27.4$ & 20.2 \\
\hline SAGETON5 & 21 & 23 & 17.3 & 0.88 & $15.7-18.4$ & 2.7 & $14.4-20.2$ & 5.8 & $13.4-21.2$ & 7.8 \\
\hline
\end{tabular}

Table 14. - The observed, standard population and probable maximum ranges of samples of lengths of smaller basitrich nematocysts from just above the limbus of Sagartiogeton laceratus. All abbreviations for headings and units for parameters as for Table 13 .

\begin{tabular}{|c|c|c|c|c|c|c|c|c|c|c|}
\hline Dataset & PDD & $\mathrm{n}$ & Mean & SD & $\begin{array}{l}\text { Observed } \\
\text { sample } \\
\text { extremes }\end{array}$ & $\begin{array}{l}\text { Observed } \\
\text { sample } \\
\text { range }\end{array}$ & $\begin{array}{c}\text { Standard } \\
\text { extremes } \\
(\mathrm{n}=1,000)\end{array}$ & $\begin{array}{l}\text { Standard } \\
\text { range } \\
(\mathrm{n}=1,000)\end{array}$ & $\begin{array}{l}99 \% \text { probable } \\
\text { maximum } \\
\text { extremes }\end{array}$ & $\begin{array}{l}99 \% \text { probable } \\
\text { maximum } \\
\text { range }\end{array}$ \\
\hline SAGETON2 & 16 & 10 & 8.9 & 0.58 & $8.3-9.7$ & 1.4 & $7.0-10.8$ & 3.8 & $3.0-14.8$ & 11.8 \\
\hline SAGETON3 & 4 & 7 & 9.0 & 1.45 & $7.4-11.1$ & 3.7 & $4.3-13.7$ & 9.4 & $1.1-16.9$ & 15.8 \\
\hline
\end{tabular}

TABLE 15. - The observed, standard population and probable maximum ranges of samples of lengths of basitrich nematocysts from just above the limbus of Urticina eques. All abbreviations for headings and units for parameters as for Table 13 .

\begin{tabular}{|c|c|c|c|c|c|c|c|c|c|c|}
\hline Dataset & PDD & $\mathrm{n}$ & Mean & SD & $\begin{array}{l}\text { Observed } \\
\text { sample } \\
\text { extremes }\end{array}$ & $\begin{array}{l}\text { Observed } \\
\text { sample } \\
\text { range }\end{array}$ & $\begin{array}{c}\text { Standard } \\
\text { extremes } \\
(\mathrm{n}=1,000)\end{array}$ & $\begin{array}{c}\text { Standard } \\
\text { range } \\
(\mathrm{n}=1,000)\end{array}$ & $\begin{array}{l}99 \% \text { probable } \\
\text { maximum } \\
\text { extremes }\end{array}$ & $\begin{array}{l}99 \% \text { probable } \\
\text { maximum } \\
\text { range }\end{array}$ \\
\hline URTIC4 & 37 & 50 & 18.1 & 0.78 & $16.6-19.8$ & 3.2 & $15.6-20.6$ & 5.0 & $14.9-21.3$ & 6.4 \\
\hline URTIC5 & 12 & 50 & 17.9 & 1.14 & $15.2-20.3$ & 5.1 & $14.2-21.6$ & 7.4 & $13.3-22.6$ & 9.3 \\
\hline
\end{tabular}

TABLE 16. - The observed, standard population and probable maximum ranges of samples of lengths of larger basitrich nematocysts from just above the limbus of Sagartiogeton laceratus. All abbreviations for headings and units for parameters as for Table 13 .

\begin{tabular}{lcccccccc}
\hline Dataset & PDD & $\mathrm{n}$ & Mean & SD & $\begin{array}{c}\text { Observed } \\
\text { sample } \\
\text { extremes }\end{array}$ & $\begin{array}{c}\text { Observed } \\
\text { sample } \\
\text { range }\end{array}$ & $\begin{array}{c}\text { Standard } \\
\text { extremes } \\
(\mathrm{n}=1,000)\end{array}$ & $\begin{array}{c}\text { Standard } \\
\text { range } \\
(\mathrm{n}=1,000)\end{array}$ \\
\hline SAGETON2 & 16 & 40 & $17.5^{\mathrm{a}}$ & 1.36 & $13.8-19.3$ & 5.5 & $13.1-21.9$ & 8.8 \\
maximum \\
extremes \\
SAGETON4
\end{tabular}

${ }^{a}$ Statistically significantly different from each other $(\mathrm{P}<<0.00001)$.

1) First, three examples of pairs of conspecific, unequal-sized anemones, from which samples of cnida lengths proved to have the same or closely similar means, were examined.

The members of the first of these pairs (Table 13) had a $>5$-fold difference in pedal disk diameter. The observed sample range of dataset SAGETON3 was $45.5 \%$ of the $99 \%$ maximum standard range, and the observed sample range of SAGETON5 was $34.6 \%$ of the $99 \%$ maximum standard range. The extremes of the 99\% maximum standard range of SAGETON5 were completely contained by the extremes of SAGETON3, with coincident means.
The specimens of the second pair (Table 14) had a 4-fold difference in pedal disk diameter, the smaller specimen being an asexually produced fragment of the larger. The observed sample ranges of SAGETON2 and SAGETON3 were $11.9 \%$ and $23.4 \%$, respectively, of the $99 \%$ maximum standard ranges. The extremes of the $99 \%$ maximum standard range of SAGETON2 were completely contained by the extremes of SAGETON3, with almost coincident means.

The specimens of the third pair (Table 15) had a $>3$-fold difference in pedal disk diameter. The observed sample ranges of URTIC4 and URTIC5 
Table 17. - The observed, standard population and probable maximum ranges of samples of lengths of smaller basitrich nematocysts from just above the limbus of Sagartiogeton laceratus. All abbreviations for headings and units for parameters as for Table 13.

\begin{tabular}{|c|c|c|c|c|c|c|c|c|c|c|}
\hline Dataset & PDD & $\mathrm{n}$ & Mean & SD & $\begin{array}{l}\text { Observed } \\
\text { sample } \\
\text { extremes }\end{array}$ & $\begin{array}{l}\text { Observed } \\
\text { sample } \\
\text { range }\end{array}$ & $\begin{array}{c}\text { Standard } \\
\text { extremes } \\
(\mathrm{n}=1,000)\end{array}$ & $\begin{array}{c}\text { Standard } \\
\text { range } \\
(\mathrm{n}=1,000)\end{array}$ & $\begin{array}{l}99 \% \text { probable } \\
\text { maximum } \\
\text { extremes }\end{array}$ & $\begin{array}{l}99 \% \text { probable } \\
\text { maximum } \\
\text { range }\end{array}$ \\
\hline SAGETON1 & 16 & 11 & $9.2^{\mathrm{a}}$ & 0.41 & $8.7-10.1$ & 1.4 & $7.9-10.5$ & 2.6 & $7.2-11.2$ & 4.0 \\
\hline SAGETON4 & 15 & 9 & $7.5^{\mathrm{a}}$ & 0.45 & $6.4-7.8$ & 1.4 & $6.0-9.0$ & 3.0 & $5.2-9.8$ & 4.6 \\
\hline
\end{tabular}

${ }^{a}$ Statistically significantly different from each other $(\mathrm{P}<<0.0001)$.

TABLE 18. - The observed, standard population and probable maximum ranges of samples of lengths of microbasic $p$-mastigophore nematocysts from the free ends of acontia of Sagartia elegans. All abbreviations for headings and units for parameters as for Table 13.

\begin{tabular}{|c|c|c|c|c|c|c|c|c|c|c|}
\hline Dataset & PDD & $\mathrm{n}$ & Mean & SD & $\begin{array}{l}\text { Observed } \\
\text { sample } \\
\text { extremes }\end{array}$ & $\begin{array}{l}\text { Observed } \\
\text { sample } \\
\text { range }\end{array}$ & $\begin{array}{l}\text { Standard } \\
\text { extremes } \\
(\mathrm{n}=1,000)\end{array}$ & $\begin{array}{l}\text { Standard } \\
\text { range } \\
(\mathrm{n}=1,000)\end{array}$ & $\begin{array}{l}99 \% \text { probable } \\
\text { maximum } \\
\text { extremes }\end{array}$ & $\begin{array}{l}99 \% \text { probable } \\
\text { maximum } \\
\text { range }\end{array}$ \\
\hline SAGART3 & 25 & 50 & $52.8^{\mathrm{a}}$ & 6.07 & $43.8-62.6$ & 18.8 & $33.1-72.5$ & 39.4 & $28.1-77.6$ & 49.5 \\
\hline SAGART4 & 9 & 25 & $61.2^{\mathrm{a}}$ & 3.91 & $51.6-69.1$ & 17.5 & $48.6-73.9$ & 25.3 & $43.9-78.5$ & 34.6 \\
\hline
\end{tabular}

${ }^{\text {a }}$ Statistically significantly different from each other $(\mathrm{P}<0.0001)$.

TABLE 19. - The observed, standard population and probable maximum ranges of samples of lengths of basitrich nematocysts from just above the limbus of Urticina eques. All abbreviations for headings and units for parameters as for Table 13.

\begin{tabular}{lcccccccccc}
\hline Dataset & PDD & $\mathrm{n}$ & Mean & SD & $\begin{array}{c}\text { Observed } \\
\text { sample } \\
\text { extremes }\end{array}$ & $\begin{array}{c}\text { Observed } \\
\text { sample } \\
\text { range }\end{array}$ & $\begin{array}{c}\text { Standard } \\
\text { extremes } \\
(\mathrm{n}=1,000)\end{array}$ & $\begin{array}{c}\text { Standard } \\
\text { range }(\mathrm{n}=1,000)\end{array}$ & $\begin{array}{c}99 \% \text { probable } \\
\text { maximum } \\
\text { extremes }\end{array}$ & $\begin{array}{c}99 \% \text { probable } \\
\text { maximum } \\
\text { range }\end{array}$ \\
\hline URTIC2 & 30 & 50 & $16.7^{\mathrm{a}}$ & 2.37 & $12.4-20.7$ & 8.3 & $9.0-24.4$ & 15.4 & $7.1-26.4$ & 19.3 \\
URTIC3 & 150 & 50 & $19.5^{\mathrm{a}}$ & 0.81 & $18.0-22.1$ & 4.1 & $16.8-22.1$ & 5.3 & $16.2-22.8$ & 6.6 \\
\hline
\end{tabular}

${ }^{\text {a }}$ Statistically significantly different from each other $(\mathrm{P}<0.0001)$.

were $50.0 \%$ and $54.8 \%$, respectively, of the $99 \%$ maximum standard ranges. The extremes of the $99 \%$ maximum standard range of URTIC4 were completely contained by the extremes of URTIC5, with almost coincident means.

The above calculations confirm the prediction of Simpson (1980) that standard range extremes are considerably wider than observed sample extremes and also show how overlap of distributions may be complete when the mean cnida sizes are the same or nearly so. In each of the three examples above, two conspecific anemones were indistinguishable by comparison both of the means and of the maximum standard ranges of lengths of one type of cnida, despite the great size difference between the specimens within each pair. The statistical comparisons of these particular types of cnida therefore led to the same correct conclusion, viz., that they were derived from the same species of anemone, assuming that other anatomical features were also similar.

2) Second, two examples of pairs of conspecific, approximately equal-sized anemones, from which samples of cnida lengths proved to have statistically significantly different means, were examined. Are the same specimens also distinguishable by the extreme values of the ranges of their cnida lengths?

For the first of these pairs (Table 16), the observed sample ranges of SAGETON2 and SAGETON4 were $48.2 \%$ and $43.4 \%$, respectively, of the $99 \%$ maximum standard ranges. The extremes of the observed sample ranges overlapped by $45.9 \%$. The extremes of the standard range of SAGETON2 overlapped the extremes of SAGETON4 by $45.7 \%$. This shows that, whilst the mean cnida lengths were significantly different by an objective statistical method, the extreme values of the observed sample ranges from two conspecific specimens were not clearly separable, nor were the extremes of the standard ranges. The extremes of the $99 \%$ maximum standard range of SAGETON2 overlapped the extremes of the range of SAGETON4 by $54.5 \%$, an increase of $\mathrm{ca} 9$ percentage points over the standard range extremes.

In the case of the second pair (Table 17), the observed sample ranges of SAGETON1 and SAGETON4 were $35.0 \%$ and $30.4 \%$, respectively, of the 
99\% maximum standard ranges. There was no overlap between the extremes of the observed ranges from the two specimens, which appears to confirm, though misleadingly (see Simpson, 1980), the statistically significant difference demonstrated between the means of the cnida lengths of the two specimens. However, using the extremes of the standard range, there was an overlap of $28.2 \%$, which is more logical, considered biologically, since we are dealing with equal sized, conspecific specimens. The 99\% maximum standard range extremes for SAGETON1 cnida lengths were 7.2-11.2 $\mu \mathrm{m}$, and those for SAGETON4 were 5.2-9.8 $\mu \mathrm{m}$. These extremes of the range of SAGETON1 overlapped those of SAGETON4 by $49.8 \%$, an increase of $c a 22$ percentage points over the standard range extremes. This demonstrates that a non-overlap of observed sample ranges of cnida lengths may misleadingly indicate that samples from conspecific anemones might be from different species. In this case, the same incorrect conclusion was reached using inferential statistical treatment of the mean cnida lengths of the same samples. However, the overlaps of extreme values of the standard ranges and the $99 \%$ maximum standard ranges led to the correct conclusion, that the two anemones examined were, in this case, conspecific.

Both of the last two examples show that there may be considerable overlap of $99 \%$ maximum standard range extremes of cnida lengths in samples from conspecific anemones, even when the mean lengths are statistically significantly different. The comparison of means or of extreme values of standard ranges may sometimes, therefore, lead to different conclusions regarding the species of anemone from which the samples were taken. The second of these examples also shows that observed sample extremes from two conspecific anemones may not overlap, providing misleading confirmation of an already incorrect conclusion based on a statistically significant difference between mean lengths of cnidae from the same specimens.

3) Third, two examples of pairs of conspecific, unequal-sized anemones, from which samples of cnida lengths had statistically significantly different means, were examined. Are the same specimens also distinguishable using the extreme values of their cnida lengths?

The first of these examples comprises SAGART3 and SAGART4 (Table 18), the observed sample ranges of which were $38.0 \%$ and $50.6 \%$, respectively, of the $99 \%$ maximum standard ranges. Whilst the extremes of the observed ranges from the two specimens overlapped by $46.7 \%$, those of the standard ranges overlapped by $91.2 \%$, and those of the $99 \%$ maximum ranges overlapped by $95.7 \%$.

The second pair, URTIC2 and URTIC3 (Table 19), had observed sample ranges $43.0 \%$ and $62.1 \%$, respectively, of the $99 \%$ maximum standard ranges. The extremes of the observed ranges overlapped by $56.3 \%$. However, with regard to the standard range and the 99\% maximum range, the extremes of URTIC3 were completely contained by the extremes of URTIC2.

In both of the above examples, the conclusion drawn from comparisons of the distributions of cnida measurements was the correct one, that the anemones of each pair were conspecific, which is the opposite of the incorrect conclusion based upon comparisons of means.

\section{Summary of suitability of various statistical criteria for identifications of pairs of anemones based upon cnida measurements}

Table 20 summarizes the conclusions reached when four different statistical criteria were used in attempts to demonstrate conspecificity within pairs of anemones, based upon cnida measurements.

TABLE 20. - Summary of correctness of conclusions regarding identifications of pairs of conspecific anemones, using four different statistical comparisons. $\mathrm{C}=$ correct conclusion; $\mathrm{I}=$ incorrect conclusion.

\begin{tabular}{|c|c|c|c|c|c|}
\hline Table number & Datasets & Mean & Observed range & Standard range & $99 \%$ maximum range \\
\hline 13 & SAGETON3 \& 5 & $\mathrm{C}$ & $\mathrm{C}$ & $\mathrm{C}$ & $\mathrm{C}$ \\
\hline 14 & SAGETON2 \& 3 & $\mathrm{C}$ & $\mathrm{C}$ & $\mathrm{C}$ & $\mathrm{C}$ \\
\hline 15 & URTIC4 \& 5 & $\mathrm{C}$ & $\mathrm{C}$ & $\mathrm{C}$ & $\mathrm{C}$ \\
\hline 16 & SAGETON2 \& 4 & I & $\mathrm{C}$ & $\mathrm{C}$ & $\mathrm{C}$ \\
\hline 17 & SAGETON1 \& 4 & I & I & $\mathrm{C}$ & $\mathrm{C}$ \\
\hline 18 & SAGART3 \& 4 & I & $\mathrm{C}$ & $\mathrm{C}$ & $\mathrm{C}$ \\
\hline 19 & URTIC2 \& 3 & I & $\mathrm{C}$ & $\mathrm{C}$ & $\mathrm{C}$ \\
\hline \multicolumn{2}{|c|}{ Total correct conclusions } & $3 / 7$ & $6 / 7$ & $7 / 7$ & $7 / 7$ \\
\hline
\end{tabular}


The least effective criterion (3/7 correct conclusions) was the comparison of mean cnida lengths (see also Williams, 1996, 1998). Although the observed range was somewhat more useful (6/7 correct conclusions), it is clear that occasionally the extremes of cnida measurements from conspecific anemones did not overlap; this confirms the principle of Simpson (1980). All the conclusions were correct only when the standard range or the $99 \%$ maximum range was used as a criterion. Clearly, it is safer to use the $99 \%$ maximum range. It may be that the practice of non-random sampling by a purposeful search to find the largest and smallest cnidae in a sample (e.g., Hand, 1955; England, 1987) would reveal range extremes close to the standard range, or even the $99 \%$ maximum range, but this has yet to be critically examined.

Fautin (1988) concluded that, because of variability in methodology and uncertainty about the significance of then current information, the use of cnidae as taxonomic characters is precluded at all but the grossest level (i.e., substantially non-overlapping ranges, or presence of unusual types) for actiniarian species determinations. The results reported here and previously (Williams, 1996, 1998), indicate that that conclusion is correct. These extensive statistical studies have shown that comparisons of means or observed extremes of sample ranges of cnida lengths are unreliable criteria. The most reliable criterion for the identification of different species, which should be subjected to further testing, is a lack of overlap of the $99 \%$ probable maximum range extremes, based upon a standard abundance of 1,000 .

It should not be forgotten that even when anemone specimens possess the same cnidome and the cnida sizes are statistically inseparable, they may still be representatives of different species, and therefore other taxonomic characters must always be taken into consideration (Williams, 1998).

\section{CONCLUSIONS}

1) Examination of five measures of dispersion of cnida lengths indicates that cnida size expressed as extreme values of observed ranges is not a reliable taxonomic character. Only complete lack of overlap of 99\% maximum standard ranges of cnida lengths may indicate reliably that samples are not from conspecific anemones.

2) Simpson's principle regarding range as a zoo- logical character is applicable to actiniarian cnida measurements, and his maximum standard range from standard deviation, adopting the 99\% probable maximum value of mean range in samples of 1,000, gives the greatest and, therefore, the most cautious estimate of a population range.

3) From the statistical standpoint, the concept that non-overlapping extremes of cnida measurements from different sea anemone specimens might indicate that they belong to different species, could be erroneous if observed sample ranges, rather than population ranges, are used. The practice of pooling data from multiple tissue samples and/or individual anemones, although statistically invalid, might result in extreme sizes that tend to approach those of population ranges.

4) From the biological standpoint, overlapping, or even completely coincident, maximum standard ranges do not necessarily indicate that anemone specimens are conspecific, since other taxonomic characters may reveal specific differences.

5) The coefficient of variation of a sample of cnida measurements may provide a useful clue as to sample heterogeneity when supported by a graphical representation of the frequency distribution.

6) The fundamental parameters of a normal frequency distribution of cnida measurements, i.e., the mean and standard deviation, can be estimated with reasonable confidence from data comprising only the extreme sizes and number of cnidae measured, as long as they were randomly collected.

\section{RECOMMENDATIONS}

A) Before attempting to compare observed sample ranges of actiniarian cnida lengths (for whatever purpose), they should be converted to Simpson's 99\% probable maximum standard range, for standard abundance of 1,000. An observed sample range does not reflect the true population range.

B) For taxonomic purposes, the only result of a comparison of maximum standard ranges that is likely to be useful is a lack of overlap between the extreme values of the ranges, which may be regarded as reliable evidence that the samples being compared originated from specimens of different species. No other result arising from comparisons between ranges of cnida lengths is likely to lead to reliable conclusions about the identity of anemone specimens, and should not, therefore, be employed for taxonomic inference. 
C) Any overlap of maximum standard ranges of cnida measurements should not automatically be interpreted as an indication of conspecific anemones. Other taxonomic characters should be taken into account.

\section{REFERENCES}

Carlgren, O. - 1900. Ostafrikanische Actinien. Mitt. Naturh. Mus. Hamburg, 17: 1-124.

Chintiroglou, C. and J. C. den Hartog. - 1995. Additional records of Actiniaria (Anthozoa) from Greece. Zool. Med. Leiden, 69: 353-364.

Cutress, C.E. - 1955. An interpretation of the structure and distribution of cnidae in Anthozoa. Syst. Zool., 4: 120-137.

Dunn, D.F. - 1981. The clownfish sea anemones: Stichodactylidae (Coelenterata: Actiniaria) and other sea anemones symbiotic with pomacentrid fishes. Trans. Am. Phil. Soc., 71(1): 1-115.

England, K.W. - 1971. Actiniaria from Mururoa Atoll, Tuamotu, Polynesia (Hormathiidae: Calliactis polypus, Sagartiidae: Verrillactis $\mathrm{n}$. gen. paguri). Cah. Pacif., 15: 23-40.

England, K.W. - 1987. Certain Actiniaria (Cnidaria, Anthozoa) from the Red Sea and tropical Indo-Pacific Ocean. Bull. Br. Mus. nat. Hist. (Zool.), 53: 205-292.

England, K.W. - 1988. Redefinitions and systematics of Heteractis aurora, the genera Heteractis and Radianthus, and the family Heteractidae (Cnidaria: Actiniaria). Indo-Malayan Zool., 5: 4555.

England, K.W. - 1990. Description of two new mud-dwelling actiniids from Maharashtra, India: Edwardsia athalyei sp. nov. and Acontiactis gen. nov. gokhaleae sp. nov. and a note on Edwardsioides mammillata (Bourne, 1916) (Cnidaria: Actiniaria). Indo-Malayan Zool., 6 (for 1989): 141-158.

England, K.W. - 1991. Nematocysts of sea anemones (Actiniaria, Ceriantharia and Corallimorpharia: Cnidaria): nomenclature. Hydrobiologia, 216/217: 691-697.

England, K.W. - 1992. Actiniaria (Cnidaria: Anthozoa) from Hong Kong with additional data on similar species from Aden, Bahrain and Singapore. In: B. Morton (ed.), The Marine Fauna and Flora of Hong Kong and Southern China III, pp. 49-95. Hong Kong University Press, Hong Kong.

Fautin, D.G. - 1988. Importance of nematocysts to actinian taxonomy. In: D.A. Hessinger and H.M. Lenhoff (eds.), The Biology of Nematocysts, pp. 487-500. Academic Press Inc., San Diego.

Fautin, D.G. and F.-S. Chia. - 1986. Revision of sea anemone genus Epiactis (Coelenterata: Actiniaria) on the Pacific coast of North America, with descriptions of two new brooding species. Can. J. Zool., 64: 1665-1674.

Hand, C. - 1955. The sea anemones of Central California, part I. The corallimorpharian and athenarian anemones. Wasmann $J$. Biol., 12 (for 1954): 345-375.
Hand, C. - 1956. The sea anemones of Central California, part III. The acontiarian anemones. Wasmann J. Biol., 13 (for 1955): 189-251.

Lindley, D.V. and J.C.P. Miller. - 1964. Cambridge Elementary Statistical Tables. Cambridge University Press, London, $36 \mathrm{pp}$.

Mariscal, R.N. - 1974. Nematocysts. In: L. Muscatine and H.M. Lenhoff (eds.), Coelenterate Biology: Reviews and New Perspectives, pp. 129-178. Academic Press Inc., New York.

Riemann-Zürneck, K. - 1997. A hemisessile sea anemone from the Porcupine Abyssal Plain, North Atlantic Ocean; Iosactis vagabunda gen. nov., sp. nov. J. mar. biol. Ass. U. K., 77: 10111025.

Simpson, G.G. - 1980. Why and How: Some Problems and Methods in Historical Biology. Pergamon Press, Oxford, 263 pp.

Simpson, G.G. and A. Roe. - 1939. Quantitative Zoology. lst edition. McGraw-Hill Book Company, New York, 414 pp.

Simpson, G.G., A. Roe and R.C. Lewontin. - 1960. Quantitative Zoology. 2nd edition. Harcourt, Brace and World, Inc., New York, $440 \mathrm{pp}$.

Snedecor, G.W. and W.G. Cochran. - 1967. Statistical Methods. 6th edition. Iowa State University Press, Ames, Iowa, 593 pp.

Snedecor, G.W. and W.G. Cochran. - 1980. Statistical Methods. 7th edition. Iowa State University Press, Ames, Iowa, $507 \mathrm{pp}$.

Stephenson, T.A. -1929 . On the nematocysts of sea anemones. $J$. mar. biol. Ass. U.K., 16: 173-201.

Watzl, O. - 1922. Die Actiniarien der Bahamainseln. Ark. Zool., 14(24): 1-89.

Weill, R. - 1926. Existence, chez certains Coelentérés, d'un cnidome spécifique, caractéristique de l'état larvaire. L'interprétation des monocnidomes. Bull. Soc. Zool. Fr., 51: 254-260.

Weill, R. - 1934a. Contribution a l'étude des Cnidaires et de leurs nématocystes. I. Recherches sur les nématocystes (morphologie - physiologie - développement). Trav. Stn zool. Wimereux, 10: 1-347.

Weill, R. - 1934b. Contribution a l'étude des Cnidaires et de leurs nématocystes. II. Valeur taxonomique du cnidome. Trav. Stn zool. Wimereux, 11: 349-701.

Williams, R.B. - 1975. Catch-tentacles in sea anemones: occurrence in Haliplanella luciae (Verrill) and a review of current knowledge. J. nat. Hist., 9: 241-248.

Williams, R.B. - 1981. A sea anemone, Edwardsia meridionalis sp. nov., from Antarctica and a preliminary revision of the genus Edwardsia de Quatrefages, 1841 (Coelenterata: Actiniaria). Rec. Aust. Mus., 33: 325-360.

Williams, R.B. - 1996. Measurements of cnidae from sea anemones (Cnidaria: Actiniaria): statistical parameters and taxonomic relevance. Sci. Mar., 60: 339-351.

Williams, R.B. - 1998. Measurements of cnidae from sea anemones (Cnidaria: Actiniaria), II: further studies of differences amongst sample means and their taxonomic relevance. Sci. Mar., 62: 361-372.

Woolf, C.M. - 1968. Principles of Biometry. D. Van Nostrand Company Inc., Princeton, $359 \mathrm{pp}$.

Scient. ed.: R. Hughes 


\section{APPENDIX I}

\section{Previous publications: estimation of standard deviations from observed ranges of pooled or confounded samples}

When extracting data from previous publications in order to estimate validly a standard deviation from an observed range, it is necessary to know the exact source(s) of the data, whether they are homogeneous, and whether they were collected randomly. Such information is often surprisingly difficult to ascertain.

For instance, suppose that an author had provided extremes of measurements for different cnida types, each with the number of observations; and that there was a statement that the samples were taken from, say, eight anemones. If the extremes of measurements for one particular cnida type comprised 40 observations, it would not be clear whether, for instance, 5 cnidae might have been measured from each specimen; or 30 from one specimen, 10 from another, and none from the rest; or, maybe, whether all the observations might have come from one specimen. Furthermore, the situation may well differ for each set of measurements from different cnida types, because researchers do not necessarily take samples from all the tissues in every specimen. In such a case, no safe assumption could be made, but in the simplest situation it might be assumed that all the cnidae measured were from one sample. Entering Snedecor and Cochran's (1967) Table 2.4.1 at $n=40$ would give an efficiency of $53.6 \%$ for estimation of a standard deviation from the observed range. However, if it were assumed that each sample comprised 5 cnidae, the mean efficiency would be $95.5 \%$.

An instructive example of the difficulties encountered in the interpretation of such data is provided in a paper by Dunn (1981), in which for each cnida type in each kind of tissue she gave the number of cnidae measured $(n)$ and the number of anemones examined $(\mathrm{N})$. Extremes of possible interpretations are provided by examples where $n=510$ and $\mathrm{N}=45$ (basitrichs in tentacles of Entacmaea quadricolor (Rüppell and Leuckart)); and $n=3$ and $\mathrm{N}=3$ (microbasic $p$-mastigophores from the column of Stichodactyla tapetum (Ehrenberg)).

Examples of the usefulness of Snedecor and Cochran's (1967) Table 2.4.1 in predicting sample standard deviations from sample ranges have already been given for normal frequency distribu- tions. However, in Table 11 (derived from Table 5 of Williams (1996)), a bimodal population of cnidae was sampled. Only subsets 1 and 4 happen to be unimodal (normal) and thus have by far the smallest standard deviations, coefficients of variation and ranges. Despite this, there is still fairly good agreement between the calculated sample standard deviations and those estimated (EstSD) from the sample $(n=5-50)$ ranges. In $6 / 11$ cases ( $c a 55 \%)$, the difference (\% diffSD) between the actual and estimated standard deviations was $\leq 10 \%$, and in $8 / 11$ cases ( $\mathrm{ca} 73 \%$ ) it was $\leq 15 \%$. This is not very different from the degree of agreement found for normal distributions (Tables 1-9) and demonstrates that the prediction method used is quite robust. For the subsets of 5 measurements, all 10 percentage differences between calculated and estimated standard deviations are not statistically significantly different, although that for the whole dataset is $(\mathrm{P}<0.05)$. However, when the two overlapping normal populations, L and S, are separated, the agreements between actual and estimated standard deviations are much closer, as expected (Table 12).

With regard to the means, it can be seen that the percentage difference (\% diffM) between the mean and the median (EstM) of cnida lengths is $\leq 5 \%$ in $5 / 11$ cases ( $\mathrm{ca} 45 \%$ ), and $\leq 10 \%$ in $8 / 11$ cases ( $\mathrm{ca} 73 \%$ ) (Table 11). This is rather a poor degree of agreement, compared with normal frequency distributions (Tables 1-9), due again to the overlapping of the two distributions. The agreement is much improved, however, when they are separated (Table 12).

Thus, for homogeneous data, the fundamental parameters of a normal distribution of cnida measurements, i.e., the mean and standard deviation, may be fairly accurately estimated from published literature which gives only the extreme sizes and number of cnidae measured. Although this information should not be used in isolation for taxonomic purposes, it may nevertheless be used when appropriate for other types of study.

The fact should not be overlooked that, when size ranges of cnidae are given for multiple tissue samples and/or several individual anemones, the resulting range tends to approach the population range more closely than homogeneous samples collected randomly from single anemones. However, the frequently encountered lack of detailed information with regard to the sources of such data unfortunately precludes their valid use in statistical estimations. 


\section{APPENDIX II}

\section{Calculation of percentage overlaps of distributions}

Quantification of the overlaps of distributions, i.e., the extreme values of ranges, is not, perhaps, as straightforward as it may at first appear. The methods used in this paper for calculating percentage overlaps in different situations are, therefore, described here. The calculations should be used only for the quantification of overlaps of distributions based upon Simpson's 99\% maximum standard range which, as explained previously, is the most conservative estimate of range. The arithmetic would, of course, still work with the observed sample range, but the results would be misleading.

First of all, the notation used for pairs of ranges to be compared is defined as follows:

Let $R_{1}$ be the greater (or equal) range, and let $E_{1 \min }$ and $E_{1 \max }$ be its smallest and largest extreme values, respectively. Similarly, let $R_{2}$ be the lesser (or equal) range, and let $E_{2 \min }$ and $E_{2 \max }$ be its smallest and largest extreme values, respectively.

The calculations used to quantify overlaps are slightly different in various situations, although the underlying principles are the same. The possible situations are:

1) $R_{1}=R_{2}$

1a) When $E_{1 \min }=E_{2 \min }$ and, therefore, $E_{1 \max }=$ $E_{2 \max }$ the ranges are perfectly coincident and the degree of overlap equals $100 \%$, which is self-evident, and no calculation is necessary.

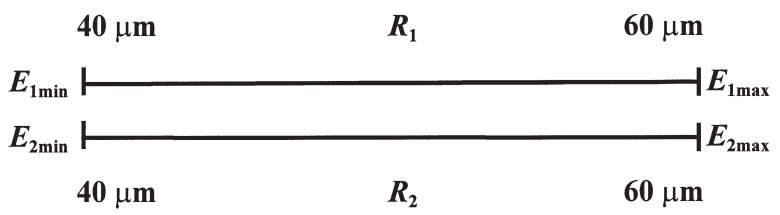

1b) When $E_{1 \min } \geq E_{2 \max }$ the degree of overlap equals $0 \%$, which is self-evident, and no calculation is necessary.

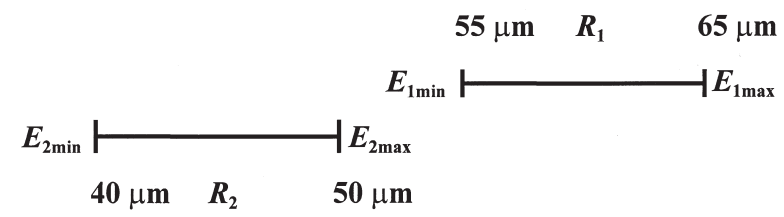

$E_{2 \min }$

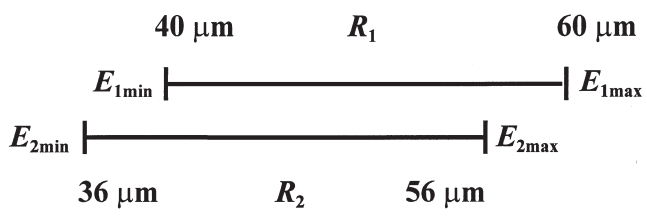

Overall range $=E_{1 \max }-E_{2 \min }=60-36=24 \mu \mathrm{m}$

Overlap $=E_{2 \max }-E_{1 \text { min }}=56-40=16 \mu \mathrm{m}$

Let $P O$ be percentage overlap:

$P O=(16 \times 100) \div 24=66.7 \%$

2) $R_{1} \neq R_{2}$

In such cases, a range equalization factor (REF) is first calculated:

Let $R E F=R_{1} \div R_{2}$

Since $R_{1} \geq R_{2}$, the $R E F$ is always $\geq 1$. A corrected $P O(P O \times R E F)$ is necessary for consistency in such cases. Its use when $R_{1}=R_{2}$ is implicit, since the $R E F$ in those cases is equal to unity as in 1c) above.

2a) When $E_{1 \text { min }} \leq E_{2 \min }$ and $E_{1 \max } \geq E_{2 \max }$

The necessity for the application of an $R E F$ when $R_{1} \neq R_{2}$ becomes apparent when examples are worked out for cases such as this. In such situations, although the extremes of $R_{2}$ are completely contained within the extremes of $R_{1}$, and logically the $P O$ should be equal to $100 \%$, the result without using the REF is always $<100 \%$ (see below). However, to obtain the corrected $P O$, multiplication of the $P O$ by the $R E F$ gives the expected result of $100 \%$. For example:

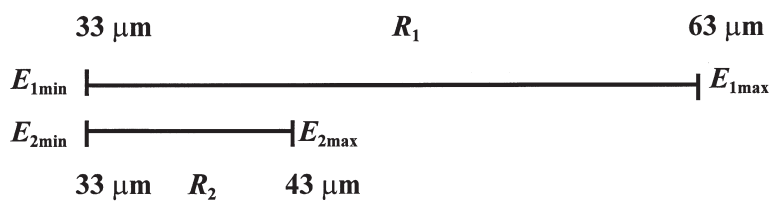

$R E F=R_{1} \div R_{2}=30 \div 10=3.0$

Overall range $=E_{1 \max }-E_{1 \min }=63-33=30 \mu \mathrm{m}$

Overlap of extreme values $=E_{2 \max }-E_{2 \min }=43-33$ $=10 \mu \mathrm{m}$

$P O=(10 \times 100) \div 30=33.33 \%$

Corrected $P O=P O \times R E F=33.33 \times 3.0=100 \%$

The same notation and calculations may be used when $E_{1 \text { min }}<E_{2 \min }$ and $E_{1 \max }>E_{2 \max }$

2b) When $E_{1 \max }>E_{2 \max }$ and $E_{2 \min }<E_{1 \text { min }}$

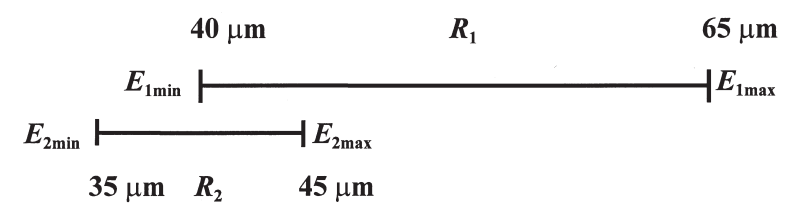

$R E F=R_{1} \div R_{2}=25 \div 10=2.5$

Overall range $=E_{1 \max }-E_{2 \min }=65-35=30 \mu \mathrm{m}$ 
Overlap of extreme values $=E_{2 \max }-E_{1 \min }=45-40$ $=5 \mu \mathrm{m}$

$P O=(5 \times 100) \div 30=16.67 \%$

Corrected $P O=P O \times R E F=16.67 \times 2.5=41.67 \%$

2c) When $E_{2 \max }>E_{1 \max }$ and $E_{1 \min }<E_{2 \min }$

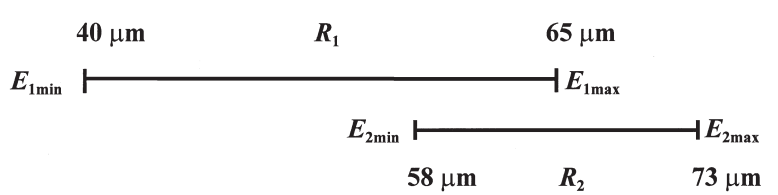

$R E F=R_{1} \div R_{2}=25 \div 15=1.67$

Overall range $=E_{2 \max }-E_{1 \text { min }}=73-40=33 \mu \mathrm{m}$

Overlap of extreme values $=E_{1 \text { max }}-E_{2 \min }=65-58$ $=7 \mu \mathrm{m}$

$P O=(7 \times 100) \div 33=21.2 \%$

Corrected $P O=P O \times R E F=21.2 \times 1.67=35.3 \%$. 